\title{
The Effect of Mood on the Perception of Facial Expressions and Social Interaction in Adults
}

Chit Yuen Yi

West Virginia University

Follow this and additional works at: https://researchrepository.wvu.edu/etd

\section{Recommended Citation}

Yi, Chit Yuen, "The Effect of Mood on the Perception of Facial Expressions and Social Interaction in Adults" (2013). Graduate Theses, Dissertations, and Problem Reports. 105.

https://researchrepository.wvu.edu/etd/105

This Thesis is protected by copyright and/or related rights. It has been brought to you by the The Research Repository @ WVU with permission from the rights-holder(s). You are free to use this Thesis in any way that is permitted by the copyright and related rights legislation that applies to your use. For other uses you must obtain permission from the rights-holder(s) directly, unless additional rights are indicated by a Creative Commons license in the record and/ or on the work itself. This Thesis has been accepted for inclusion in WVU Graduate Theses, Dissertations, and Problem Reports collection by an authorized administrator of The Research Repository @ WVU. For more information, please contact researchrepository@mail.wvu.edu. 
The Effect of Mood on the Perception of Facial Expressions and Social Interaction in Adults

\title{
Chit Yuen Yi
}

\author{
Thesis submitted to the \\ Eberly College Arts and Sciences \\ at West Virginia University \\ in partial fulfillment of the requirements \\ for the degree of
}
Master of Science
in
Psychology

\author{
Committee Members \\ Amy Gentzler, Ph.D., Chair \\ Aaron Metzger, Ph. D. \\ William Fremouw, Ph. D.
}

Department of Psychology

Morgantown, West Virginia

2012

Keywords: Emotion Perception, Mood-Congruity Effect, Mood Induction, Social Interaction Copyright 2012 Chit Yuen Yi 


\section{ABSTRACT \\ The Effect of Mood on the Perception of Facial Expressions and Social Interaction in Adults}

Chit Yuen Yi

The present study examined how mood influences perception of facial expressions, and how emotion perception predicts differences in social interactions, in a sample of 75 young adults (49 females and 26 males, 18 -37 years of age). Participants were assigned to one of the two experimental conditions in which they recalled a personally meaningful emotional event (positive vs. negative). They then completed an emotion perception task that assessed their recognition accuracy and perceived intensity of emotions. At the end of the study, they also engaged in a social interaction with a same-sex confederate while being unobtrusively observed. The results did not support the mood-congruity effect on perception of emotional expressions. However, negative mood impaired participants' performance in recognizing neutral expressions. Individuals also perceived neutral expressions as more negative after mood induction. There was evidence that mood influenced the amount of additional comments and positive affect exhibited during the social interaction and that perceived intensity of negative emotions predicted more prolonged eye contacts with the confederate. However, the present study did not find evidence of moderating or mediating effects of emotion perception on how mood influences social interaction. Limitations and future directions were also discussed. 


\section{TABLE OF CONTENT}

I. Introduction

a. Importance of Emotion Perception (pp. 1 - 2)

b. Mood-Congruity Effect on Emotion Perception (pp. 2 - 7)

c. Theoretical Background (pp. 7 -9)

d. Factors Affecting Emotion Perception (pp. 9 - 10)

e. Mood, Emotion Perception and Social Interaction (pp. 10 - 11)

f. The Present Study (pp. $12-13$ )

II. Method

a. Participants (pp. 13-14)

b. Procedure (pp. $14-17)$

c. Materials (pp. $17-25$ )

III. Results

a. Preliminary Analyses (pp. 25 - 27)

b. Research Question 1 (pp. $27-28$ )

c. Research Question 2 (pp. 28 - 31)

d. Exploratory Analyses (pp. $31-32$ )

IV. Discussion

a. Mood Effect on Recognition Accuracy of Emotions (pp. 32 - 34)

b. Mood Effect on Perceived Intensity of Emotions (p. 34)

c. Mood-congruity Effect on Emotion Perception (pp. 35 - 36)

d. Mood and Perception of Neutral Expressions (p. 36)

e. The Role of Mood and Emotion Perception on Social Interaction (pp. 36 - 38)

f. Discussion of Exploratory Findings (pp. 38 - 40)

g. Limitations and Future Directions (pp. $40-41$ )

V. References (pp. 42-50)

VI. Tables and Figures (pp. $51-61$ )

VII. Appendices (pp. 62-77) 


\section{The Effect of Mood on the Perception of Facial Expressions and Social Interaction in Adults}

Facial expressions of emotion convey important information about the emotional state of the expresser (Ekman, 1993). During everyday interactions, we often rely on the facial expression of others to judge their emotional state. The emotional messages we interpret from other's facial expression help us to make inferences about other's attitude and intention (Fridlund, 1994), to regulate our own emotions (Manstead \& Fischer, 2001) and to guide our social interaction (Keltner \& Kring, 1998). Therefore, our ability to perceive others' emotions from faces serves an important social function to help us to maintain our interpersonal relationships, to coordinate our own emotional responses, and to monitor our social behaviors. Previous studies with children and adults have linked emotion perception accuracy to better social adjustment (Leppänen \& Hietanen, 2001; Engelberg \& Sjöberg, 2004) and mental health (Lembke \& Ketter, 2002; Surguladze, Young, Senior, Brébion, Travis, \& Phillips, 2004).

Given the importance of emotion perception in regulating our social life and interpersonal communication, many researchers have investigated personal characteristics that could influence one's perception of facial expressions. A number of studies from this line of research have focused on the affective state of an individual because emotions can have a powerful influence on cognitive processes, such as perception (e.g., Persad \& Polivy, 1993; Chepenik, Cornew, \& Farah, 2007, Trevisani, Johnson, \& Carver, 2008; Schmid \& Mast, 2010). However, these investigations have largely emphasized the impact of affective state on the accuracy of emotion recognition, especially in clinical population with mood disorders (e.g., Cooley \& Nowicki, 1989; Bouhuys, Greet, \& Gordjin, 1999; Surguladzeet al., 2004; Trevisani et al., 2008). According to Thomas, De Bellis, Graham and LaBar (2007), methods that focused on the accuracy of emotion recognition were prone to ceiling effect in performance because the emotion 
recognition task was generally simple and easy. Therefore, relying on the accuracy of emotion recognition might not be sensitive enough to capture the perceptual processing of emotional facial expressions. To better tap into the perceptual process, the first goal of the present study is to examine the influence of affective state on recognition accuracy as well as perceived intensity of emotional facial expressions among healthy individuals. Although acknowledged as a key impetus for emotion perception research (Fischer \& van Kleef, 2010), the study of how perception of facial expression predicts subsequent social behaviors of the perceiver is scarce. Therefore, the second goal is to understand whether emotion perception is associated with social interaction.

\section{Mood-congruity effect on emotion perception}

Often within previous research regarding the impact of affective state on perception of facial expressions, the terms "mood" and "emotion" are used interchangeably. To avoid confusion, it is important to define these basic terms. According to Russell (2003), affect refers to the neurophysiological state that is consciously accessible as the simple, primitive and ubiquitous feelings evident in moods and emotions. It is often used as a higher order term that encompasses all affective constructs. The term "affect" is used when researchers of the reviewed studies did not specify their terminology. Mood is the affective construct that has no clear impetus or antecedent. It is mild in intensity and is long-lasting. On the other hand, emotion is the relatively short-lived and more intense affective construct. It is usually directed at a person, a condition, a thing or an event. In the present study, we asked the participants to recall an emotional life event. Although the event recall might elicit a certain emotion/emotions in our participants, we expected the manipulation to have a lasting effect on their mood. Therefore, 
more precisely, we investigated the mood effect on perception of facial expressions and social interaction.

Past research regarding the impact of affective state on emotion perception has relied on different methodologies. Vast amount of research on emotion perception of facial expression looked at people's accuracy in recognizing different basic emotions (i.e. happy, sad, anger, etc.) from static face stimuli. In these studies, participants were asked to either respond to forcedchoice questions (e.g., Ekman, Sorenson, \& Friesen, 1969; Izard, 1971; Chepeniket al., 2007; Thomas, De Beliis, Graham, \& LaBar, 2007) or to label the emotions based on what they saw in the emotion recognition task (e.g., Schiffenbauer, 1974; Surguladaze et al., 2004). Some early studies used schematic drawn emotional faces (e.g., Bouhuys, Bloem, \& Grrothuis, 1995), whereas others used prototypical emotional faces of human adults (e.g., Schiffenbauer, 1974; Chepenik et al., 2007; Schmid \& Mast, 2010). In both cases, researchers were interested in people's accuracy in recognizing facial expression of emotions under a certain affective state. A person was said to have a positive perceptual bias if he/she was less accurate in recognizing negative emotions or attributed positive emotions to neutral face stimuli under a positive affective state. If a person was less accurate in recognizing positive emotions or attributed negative emotions to neutral face stimuli under a negative affective state, he/she was consider as showing a negative perceptual bias (Schmid \& Mast, 2010).

To examine these biases in recognition of ambiguous facial emotions, some researchers have used morphed faces, in which two basic emotions (e.g., happy and anger, anger and fear, etc.) of different intensity were blended into a single facial expression (e.g., Richards, French, Calder, Webb, Fox, \& Young, 2002). These faces could be interpreted in one way or the other, depending on the perception of a person. For example, a happy-anger morphed face can be 
recognized as either happy or anger based on how participants perceive the facial expression. Studies using morphed face have provided evidence that biased judgment of facial expressions was mood-specific. Participants tended to perceive ambiguous facial expressions as displaying the emotion that was congruent with their current affective state (see van Der Veen, Evers, Deutz, \& Schmitt, 2007; Lee, Ng, Tang, \& Chan, 2008).

Together, results from these studies revealed that people show mood-specific bias in the recognition of emotional facial expressions (e.g., Cooley \& Nowicki, 1989, Chepenik et al., 2007; Lee et al., 2008; Schmid \& Mast, 2010). The rationale is that the affective state of an individual facilitates the processing of mood-congruent information and hinders the processing of mood-incongruent information (Bower, 1981). Therefore, the first part of the present study sought to examine the effect of mood on perceived intensity of prototypical emotions, in addition to accuracy in recognizing these emotions.

Past research on emotion-recognition ability mostly concerned clinical patients who have mood disorders, with a focus on mood effect on recognition accuracy and perceptual bias to emotional face stimuli (e.g., Cooley \& Nowicki, 1989; Surguladze et al., 2004). It is important to consider the studies of emotion perception among clinical patients because mood disorders represented the extreme case of mood disturbance. The existence of mood-specific perceptual bias in patients with mood disorders would provide an incentive to further understand the impact of affective state on perception of emotional facial expressions.

Previous studies regarding the nature of the impairment in perception of facial expressions in depressed patients have generated mixed results. Some researchers found evidence for a generalized deficit in recognition of all emotions (e.g., Persad \& Polivy, 1993), while others (e.g., Bouhuys et al., 1999; Gollan, McCloskey, Hoxha, \& Coccaro, 2010) reported 
negative perceptual bias in depressed patients, revealing that they were prompted to pay more attention to negative information and thus recognized more sadness in facial expressions than healthy individuals. Such discrepant findings could be attributed to different methodologies adopted in those studies. First, different studies used different types of stimuli. In some of the studies, Ekman photos were used (e.g., Persad \& Polivy, 1993), whereas other researchers used schematic drawn faces (e.g., Bouhuys et al., 1999). Second, stimuli were presented for different duration in these studies. Third, stimuli across the studies differed in the intensity of displayed emotions. For instance, Surguladzeet al. (2004) found that depressed patients, compared with healthy individuals, were less accurate in recognizing sad and happy facial expressions presented for shorter duration (100ms), but no significant difference were found when the stimuli were presented for 2000ms. Depressed patients were also less likely to identify low-intensity happy and neutral faces as happy (Surguladze et al., 2004). This finding is further supported by an event-related potential (ERP) study that provided evidence for an impaired cognitive processing ability in emotion recognition for low-intensity happy faces in depressed patients (Cavanagh \& Geisler, 2006).

Biased response to emotional face stimuli was also found in patients with mania (e.g., Lembke \& Ketter, 2002). Using functional magnetic resonance imaging (fMRI), Lennox, Jacob, Calder, Lupson and Bullmore (2004) provided evidence that Bipolar I mania patients who were in an elated mood showed deficits in recognition of sadness in faces during the behavioral task, which was accompanied by an abnormal brain activation in the paralimbic regions that are responsible for emotion recognition and mood disorders. In a recent study on individuals who are at risk for mania, Trevisani et al. (2008) found that individuals who scored higher on the Hypomanic Personality Scale performed particularly better in identifying subtle happy faces 
when in a positive mood. In general, this line of research suggested that clinical patients with mood disorders showed impaired recognition of emotional face stimuli that were incongruent with their own mood state and heightened responses to emotional face stimuli that were congruent with their mood state, especially when the face stimuli were presented for a short period of duration. Their ability to recognize emotional face stimuli was rather intact when the faces were presented for a longer duration (Surguladze et al., 2004). To understand whether there is a natural tendency to show mood-congruity effect, we investigated this effect in a normal population without a current diagnosis of depression. In particular, we examined whether there is mood-congruity effect on the recognition and perceived intensity of emotions.

To date, published research on the association between normal variation of mood and emotion perception in healthy individuals is rare. Some research focused on the effect of sad mood (e.g., Chepenik et al., 2007; Lee et al., 2008). These studies attempted to induce sad mood in healthy participants using guided imagination of an upsetting event (Chepenik et al., 2007) or sad movie clips (Lee et al., 2008). Although Chepenik and colleagues (2007) reported that participants showed a general impairment in facial emotion recognition when in a sad mood relative to a neutral mood, their results could be attributed to the cognitive overload of the participants as they were also tested on six other cognitive tasks under the induced mood. Lee and her colleagues (2008), on the other hand, found evidence for a mood-specific negative bias in the judgment of facial expressions among healthy participants who were induced to experience a sad mood. The "sad" participants, compared to those who felt happy or neutral, perceived more sadness in morphed faces, which consisted of blended expressions of a positive emotion and a negative emotion. These results are consistent with previous findings that sad 
mood in healthy participants was associated with a negative bias in the perception of emotional facial expression in line-drawn faces (Bouhuys et al., 1995).

Recent research regarding mood effects on emotion recognition in healthy participants was conducted by Schmid and Mast (2010). They extended previous research in the area by including the examination of positive mood (as well as negative mood). In the study, participants were primed to experience happy, sad or neutral mood with the corresponding mood-evoking movie clips. They were then asked to perform an emotion recognition task that contained happy and sad facial stimuli. The results revealed that sad participants recognized sad facial expressions better than happy ones (in favor of a negative bias), whereas happy participants showed a nonsignificant trend of better recognition of happy facial expression as compared to sad ones (suggesting a positive bias). Although the Bouhuy et al. (1995), Lee et al. (2008) and Schmid and Mast (2010) studies provided evidence for mood-specific perceptual bias in emotion recognition, they solely focused on the accuracy of emotion recognition. The present study further examined participants' perceived intensity of the emotions, in addition to their accuracy in recognizing emotions after mood induction.

\section{Theoretical background}

Three cognitive theories or phenomena could explain why one's affective states may influence the processing of emotional information in facial stimuli: 1) mood-congruity effect (Bower, 1981); 2) affect infusion model (Forgas, 1995); and 3) top-down processing theory (Niedenthal \& Halberstadt, 2003). According to Bower (1981), mood-congruity effect refers to the tendency to attend to and learn more about materials that match ones' mood states. This tendency can be explained by the semantic-network theory, which suggests that we form a network of association among different semantic concepts and schemas to help us make sense of 
the world. Activation of one concept would lead to the activation of other concepts along the associative network. This theory suggests that each mood state, such as a depressed or elated state, has a specific unit in our memory that is connected with many other aspects of the mood by the associative linkages between these aspects. Therefore, the current mood state of a person would make mood-congruent materials more salient and accessible to the person, easing the processing of these materials.

Another mechanism through which our affective state may influence our perceptual processing and evaluative judgment of other's facial expression is called affect infusion. The affect infusion model (AIM), introduced by Forgas (1995), states that our affective experiences exert an influence on our judgmental process and become incorporated into the process. More precisely, our emotional feelings can directly inform our judgment during quick, heuristic processing such that we use our current mood state as a shortcut to arrive at a judgment. In support of this notion, Schwarz (1990) suggested that our mood states serve informative functions to help us make sense of the situation we are experiencing and guide our response to the situation. According to Schwarz's (1990) affect-as-information model, when we need to make evaluative judgment about something, we frequently use our mood state at the time of the judgment as a reference in making our decision. Therefore, it is reasonable to expect that people would pay more attention to emotional cues that are consistent with their own mood states. In the context of perception of facial expressions, the affective infusion model and the affect-asinformation model predict that people would consult their mood state when they need to make a quick judgment about other's emotional facial expressions, making mood-congruent information more available to their judgmental process. Therefore, emotionally-aroused individuals would be more susceptible to mood-congruity effects during emotion perception task. 
Mood states can also influence one's perception of facial expression through top-down processing (Niedenthal \& Halberstadt, 2003). According to top-down theory of information processing (Norman \& Rumelhart, 1975), we draw on information already stored in our memory to make assumption or presuppositions about the material being processed. Therefore, it is expected that our mood states would activate mood-congruent concepts, which would then be used to help us interpret other's facial expression, leading us to attribute our own emotions to other people.

\section{Factors affecting emotion perception}

In addition to the affective state of the perceiver, researchers have identified other personal characteristics that could influence the perception of emotional facial expression. For example, women generally outperformed men in tasks measuring the processing of emotional faces, such as emotion recognition task (e.g., Hall \& Matsumoto, 2004; Montagne, Kessels,

Frigerio, de Haan, \& Perrett, 2005; Hoffmann, Kessler, Eppel, Rukavina, \& Traue, 2010). Variation in attachment-related anxiety was found to relate to individual difference in sensitivity to emotional stimuli (Fraley, Niedenthal, Marks, Brumbaugh, \& Vicary, 2006). Specifically, highly anxious individuals were sensitive to changes in facial expression of emotions, but they made more errors in recognizing the displayed emotions than less anxious individuals. Maltreatment during childhood also has been associated with atypical processing of emotions. Individuals with a family history of abuse showed heightened ability in identifying fearful facial stimuli (Masten, Guyer, Hodgdon, McClure, Charney, Ernst et al, 2008) and physically-abused children have been found to exhibit enhanced perceptual sensitivity to angry facial cues (Pollack \& Kistler, 2002). Also, neglected children had more difficulty matching facial expressions to appropriate emotional situation and saw fewer distinctions between discrete emotions (Pollak, 
Cicchetti, Hornung, \& Reed, 2000). These factors would be assessed as potential covariates on the association between affective state and emotion perception if they are correlated to the perception task variables in the present study.

\section{Mood, emotion perception and social interaction}

There is empirical evidence that the affective state of individuals not only influences their perception of emotions from face stimuli, but also affects their perception of a hypothetical person and their assessment of their social relationships. Forgas and Bower (1987) found that people form favorable and positive impression-formation judgments about some hypothetical persons more frequently and more quickly when they were in a positive mood than when they were in a negative mood. A number of studies have also shown that current affective state influences individual's evaluation of social relationships in a hypothetical scenario of social interaction. For instance, angry individuals perceived less fairness in an ongoing interaction (Keltner, Ellsworth, \& Edwards, 1993), fearful individuals perceived more possible risks and losses in the context of a potential social interaction (Lerner \& Keltner, 2001). Results from these studies imply that the affective influence on emotion perception and social judgment could potentially direct the behaviors of the perceiver during social interaction. However, research that examines the subsequent behaviors of an emotionally-aroused perceiver in a social interaction is scarce. Past study that focused on aggression found that participants who grew up in the South of the United States were more likely to engage in aggressive and dominant behaviors after being agitated by a verbal insult (Cohen, Nisbett, Bowdle, \& Schwarz, 1996). Some early studies in social psychology also revealed that positive mood increased general activation of behaviors such that people in a good mood were more likely to engage in helping behavior (Batson, Coke, Card, Smith, \& Taliaferro, 1979) and initiate more conversation with the confederate (Isen, 
1970). Other research tended to focus on how an individual's expression and experience of emotion may influence another interacting person's social behaviors (e.g., Throne, 1987; Tronick, 1989).

Even less is known about how emotion perception may influence the way in which people interact with others. Research with social anxiety sample found evidence that perception of disgust expressions during a hypothetical social interaction deterred socially anxious individuals from interacting with the expressor (Schofield, Coles, \& Gibb, 2007). This result suggests that perception of negative emotional cues can serve to maintain anxiety and avoidant behaviors related to interacting with the social world. In another laboratory study, perception of fear expressions facilitated approach behaviors, whereas perception of angry expressions promoted avoidance-related behaviors in a sample of college students (Marsh, Ambady, \& Kleck, 2005). It is worth noting that Marsh and her colleagues (2005) operationalized avoidanceapproach behaviors as participants' reaction time to pull (indicative of approach behavior) or push (indicative of avoidant behavior) a lever after viewing fearful or angry face stimuli. Therefore, it is unclear whether their results would apply in a social setting. To our knowledge, no previous research has investigated the effect of one's general emotion perception on an unrelated social interaction, either in a naturally-occurring or experimentally-induced interaction. The present study attempted to fill the gap in the literature by focusing on the subsequent social behaviors of the perceiver in an unobtrusively videotaped staged social interaction. We predict that the mood state of an individual (the perceiver) would influence his/her perception of other person's emotions, which in turn, would affect his/her social behaviors during an actual interaction with another person. 


\section{The present study}

The first goal of the present study is to investigate the effect of mood on emotion recognition accuracy and perceived intensity of emotions. To better understand the social consequences of emotion perception, the second goal of the study is to test whether mood and emotion perception relate to the subsequent social behaviors of the perceiver. The study was experimental in design wherein a sample of college students were randomly assigned to either a positive or negative mood induction condition. Participants' accuracy in recognizing emotions from prototypical face stimuli and their perceived intensity of the emotions were compared across conditions. Following the emotion perception tasks, participants were unobtrusively observed as they engaged in a brief interaction with a confederate.

\section{Research question 1: Does affective state influence one's perception of facial expression?}

Hypothesis 1a. Participants in a negative mood would be less accurate in identifying mood-incongruent face stimuli (e.g., happy and surprise) than in identifying mood-congruent stimuli (e.g., anger and sad); participants in a positive mood would be less accurate in identifying mood-incongruent face stimuli (e.g., anger and sad) than in identifying mood-congruent stimuli (happy and surprise)

Hypothesis 1b.People would perceive mood-congruent expressions as more intense and mood-incongruent expressions as less intense.

Hypothesis 1c.Emotionally-aroused people would attribute their own mood to neutral expression. 


\section{Research question 2: Does perception of facial expression affect social interaction?}

Hypothesis 2a. Participants in a negative mood state would show less initiative behaviors, make less eye contact with the confederate and exhibit more negative affect during social interaction; people who are in a positive mood state would show more initiative behaviors, make more eye contact with the confederate and exhibit more positive affect during the social interaction

Hypothesis 2b. Because both a moderation and meditation model may be plausible, and there is no prior research linking emotion perception and behavior, two different models will be tested. The moderation model is based on the premise that those who rate mood-congruent faces as more intense in the emotion perception task would be more susceptible to the impact of affective state on social interaction (described in hypothesis $2 \mathrm{a}$ ). The meditational model only will be tested if the paths between mood and emotion perception and between emotion perception and behavior are significant. Support for this latter model would indicate that mood influences one's social behaviors through its effect on emotion perception of the individual.

\section{Method}

\section{Participants}

Eighty seven college students were recruited through psychology course at West Virginia University. Advertisements of the study were shown in psychology courses by instructors and posted on bulletin boards in the Psychology Department (Life Science Building). Participants received course credits in a WVU psychology class for their participation in this 1-hour lab study. Exclusion criteria included 1) age of 18 or younger, 2) currently receiving treatment for depression, and 3) previous participation in Cognitive Performance Study conducted by the same research team. Using G-Power 3.1 software (Faul, Erdfelder, Lang, \& Buchnes, 2007), it was 
determined that $\mathrm{N}=77$ would be needed to obtain power at the .80 level to detect a medium effect $\left(f^{2}=.25\right)$ at .05 significance level in an omnibus multiple regression framework with up to 3 predictors. This sample size also provided sufficient power in a mixed model ANOVA with one within-subject factor and one between-subject factor, assuming a medium effect of .25.

However, twelve out of eighty seven participants were discarded from further analyses because they knew the confederate $(n=2)$, knew the study hypotheses $(n=6)$, had missing audio data $(n=3)$ or did not give permission to use their video data $(n=1)$. The final sample of 75 young adults consisted of 26 males and 49 females between the ages of 18 and $37(M=20.67$; $S D=3.56)$. The ethnic composition of the participants was: 62 Caucasian, 6 African American, 2 Hispanic American, 2 Asian American, 1 Pacific Islander and 2 self-identified as "Others" (from Jamaica and Saudi Arabia, respectively). Majority of the participants were college freshmen or sophomores (20\% and $42.7 \%$, respectively), $26.7 \%$ were juniors, $8.3 \%$ was seniors, and $1.3 \%$ were graduate students who took an undergraduate psychology class. They were told that all of their information would be kept confidential and that they would have the right to withdraw from the study at any time without penalty. Additional demographics for the sample are shown in Table 1.

\section{Procedure}

Participants signed up for the study via the online subject recruitment system (Sona). They were given various timeslot options and could sign up for a particular lab session. Participants came into the lab at the appointed time and were informed that the study examined the effect of past experiences on judgment of facial expressions.

At the beginning of the study, participants completed the consent form that briefly described the study procedure and participant's rights. After they signed the consent form, they 
were asked to provide their basic demographic information (e.g., age, race, gender, year in college, college major, country of origin, first language), report on their psychological functioning (i.e., current and past history of psychological disorders and history of physical abuse), and complete three additional questionnaires online at the Survey Monkey site. The questionnaires assessed participants' self-reported current mood, their attachment style, and their family expressiveness of emotions. The family expressiveness questionnaires were part of an undergraduate honor thesis study. Therefore, these will not be discussed further.

After filling out the questionnaires, participants completed a baseline emotion perception task on a designated computer. In this task, participants were presented with a series of 20 faces (4 happy, 3 anger, 3 neutral, 4 surprise, $3 \mathrm{sad}$, and 3 fear) and after each one, they had to indicate the displayed emotion out of a list of possible choices (happy, sad, surprise, anger, fear, neutral) and rate how intense the emotion seemed. If their answer choice was "neutral", they would rate the valence instead of the intensity of the emotion. Following this task was the mood induction during which participants were randomly assigned to one of the two conditions: positive event recall and negative event recall, which aimed at inducing positive affect and negative affect, respectively. Participants in the positive-event group were asked to recall a recent, positive experience and describe it to the experimenter, whereas those in the negative-event group were asked to recall a recent, upsetting event. Their responses were audiotaped. Afterwards, participants took a brief mood survey as a manipulation check for the effectiveness of the mood induction. Then, they completed another emotion perception task in which they saw 52 emotional faces (10 happy, 7 anger, 11 neutral, 7 sad, 10 surprise, and 7 fear) one at a time. After each stimulus, they were asked to determine the displayed emotion out of a list of possible choices and indicate the intensity or the valence of the emotions. 
Upon their completion of the emotion perception task, the experimenter said to the participants "The study is almost over. But I have to take a look at your data before you leave. Meanwhile, I would like you to fill out the last survey online. I will be back in a few minutes." After the participants completed the last brief mood survey, a same-sex confederate pretended to came into the experiment room by accident. All confederates were kept blind to the experimental conditions. The confederate then asked the participants for permission to enter the room. Once he/she had the permission, the confederate introduced him/herself as another researcher in the lab and attempted to initiate a social conversation with the participant by making some standard icebreaker comments. Then, the confederate asked the participant for a favor in completing a simple task. What the confederate says and does were scripted and kept standardized across participants. Should the confederates know the participants from school or work, they would still serve as the confederate, but the resulted observation would be discarded in further analysis. This part of the study lasted for 2 minutes and was videotaped, without the participants being aware, for later coding of social interaction between the participants and the confederate. Due to a technical issue of recording the voice with the video camera situated outside the experiment room, we recorded the conversations with a microphone hid inside the confederate's pocket. The resulting audio tapes were synchronized with the corresponding video tapes by an undergraduate research assistant for later coding. After the 2-minute interval, the experimenter returned to the room and told the participants that the study was over. Participants were thanked and fully debriefed. Specifically, they were informed of the true purpose of the study (to investigate how emotions/mood might affect people's judgment about others' emotions and their social interaction) and were told that the interaction was videotaped for the purpose of later coding. Confederates remained in the experiment room during the debriefing to validate the 
experimenter's explanation of the true purpose of the study. Participants were given an additional consent form regarding the use of their video data. They were all given the option of withdrawing their consent for our use of any or all of their data, and they were asked not to share the true purpose of the study with other students. Participants were also given the option to view their own video before they signed the video consent form at the end of the experiment.

\section{Materials}

Demographic and psychological functioning information This set of questions

(Appendix A) consisted of a variety of background and demographic measures, including age, gender, race, country of origin, first language, year in college, college major, history of mood disorders, and physical abuse. History of mood disorders was included for all participants because previous or current diagnosis might complicate our analysis and we only want to look at the effect of normal variations of mood in currently healthy people. It is important to consider history of physical abuse because past research revealed that maltreated individuals showed atypical processing of emotions, thus might affect people's accuracy in the emotion perception task (Masten, et al., 2008). However, the question on physical abuse was added late, and thus, will not be included in further analyses.

Mood assessment Participants completed a self-reported measure of mood state (BMIS; Mayer, \& Gaschke, 1988) at three time points: (1) at the beginning of the experiment, (2) immediately after event recall, but before the experimental task of emotion perception, and (3) immediately after completing the emotion perception task. The scale lists 16 feeling states (e.g., lively, happy, sad, fed up, drowsy and active) on a 4-point Likert scale (1=definitely do not feeling, and 4 =definitely feel). The scale has been used in several studies to check the effectiveness of manipulation of mood states (Innes-Ker, \& Niedenthal, 2002; Niedenthal et al., 
2001; Niedenthal and Setterlund, 1994; Kokkonen \& Pulkkinen, 2001; Mayer, Allen, \& Beauregard, 1995). Following Mayer and Gaschke (1988) scoring instructions, positive mood state was indicated by averaging participants' ratings of happy, content, active, lively, peppy, calm, caring, and loving, whereas negative mood state was indicated by averaging their ratings on sad, gloomy, tired, drowsy, fed up, grouchy, jittery, and nervous. The BMIS has been shown to have good internal reliability for measuring positive and negative mood states (with Cronbach's $\alpha=0.86$ and 0.86 respectively; Ishii, Miyamoto, Niedenthal, \& Mayama, 2011). In present study, the reliability of BMIS ranged from .74 to .82. See Appendix B for the BMIS.

Attachment orientation To assess the global attachment pattern of the participants as a potential covariate, the participants were asked to complete the revised Experiences in Close Relationship Questionnaire (ECR-R; Fraley, Waller, \&Brennan, 2000) at the beginning of the study. This questionnaire contains 36 items designed to assess attachment-related avoidance and anxiety in close relationships. Example items are "I am nervous when my partners get too close to me" for the avoidance scale, and "My desire to be very close sometimes scares people away" for the anxiety scale. Participants rated each item on the ECR-R questionnaire on a 1 (strongly disagree) to 7 (strongly agree). Both avoidance scale $(\alpha=.93)$ and anxiety scale $(\alpha=.90)$ showed high internal consistency in present study. A copy of the ECR-R is shown in Appendix C.

Mood Induction To manipulate the mood state of participants, they were randomly assigned to one of the two groups: positive event recall and negative event recall. Participants were asked to describe a happy and an upsetting event, respectively. Recalling emotional episode has been used in previous studies to induce emotions (e.g., Schwarz \& Clore, 1983). A copy of the scripts for positive event recall and negative event recall is shown in Appendix D. Examples of positive events included family reunion and academic achievement or extra-curriculum 
accomplishment. For negative events, some recalled events tended to be more intense than the others. For instance, one participant disclosed a recent murder in the immediate family. Other topics of negative events typically involved natural death of a significant other or conflict with friends. When the participants became too upset during the event recall (e.g., cried during the recall), the experimenter offered comfort as needed and asked if they wanted to continue the study. All participants chose to complete all the procedures in the present study. At the end of the study, participants were given a referral sheet with contact information of local counseling services.

Emotion perception task. The task was delivered using PXLab software (Irtel, 2007) on a designated laptop. We used 72 black-and-white stimuli from P. Ekman's database of facial expression photographs (Ekman, \& Friesen, 1976). Stimuli contained 14 happy, 10 anger, 14 neutral, $10 \mathrm{sad}, 14$ surprise and 10 fear facial expressions. Not all photographs from the database were selected. The discarded photographs either display poser whose eyes gazed downward (in 2 sad stimuli) or show poser who display the same emotion for more than once. In the latter case, the stimuli with higher inter-rater reliability according to Ekman and Friesen (1976) were retained. Twenty faces were used in the baseline session and fifty-two in the experimental session after mood induction.

In both sessions, the face stimuli were presented one at a time at the center of the computer screen for a fixed duration of $800 \mathrm{~ms}$. This duration of time was adjusted from the 500ms used in Chepenik, Cornew and Farah (2007) to allow enough time for the participants to make identification as well as intensity judgment. Each face stimulus was preceded by a fixation cross of the same duration to direct the participants' attention to the center of the computer screen. For each stimulus, the participants were instructed to respond to a force-choice question 
regarding the type of emotion displayed by the face and to indicate their perceived intensity of the emotion on a graphic rating scale (ranged from 0 to 10) consisting of a line with not at all intense and extremely intense printed at the opposite ends. If the participants chose "neutral" for their answer, they were asked to indicate the valence of the emotion on a graph rating scale (range from -10 to 10) with negative and positive printed at the opposite ends. In the experimental session, the face stimuli were presented in standard order such that neither the poser nor the same emotion would appear consecutively. For the purpose of the study, happy and surprise were grouped as positively-valenced emotions whereas sad, anger, and fear were grouped as negatively-valenced emotions. Although the emotion of surprise is generally considered as neutral, some studies suggested that it could be categorized as a positive emotion (e.g., Lerner \& Keltner, 2000; Waugh \& Fredrickson, 2006). Participants' accuracy of emotion recognition and perceived intensity of positive and negative emotions were computed separately, yielding 2 mean measures (accuracy and intensity rating) for each valence of emotions. See Appendix E for examples of Ekman photos and the questions used in the emotion perception task.

Social interaction task. After the completion of the emotion perception task, the participant was left in the experiment room with a same-sex confederate for a 2-minute interval. Three female and one male confederate were trained to deliver the social interaction script. The confederate entered the room and introduced him/herself as another researcher in the lab. Then, the confederate launched a series of scripted icebreaker comments in an attempt to initiate a social conversation with the participants. Also, the confederate asked participants for a favor. Following the work of Schachter and Singer (1962), the confederate's act was broken down into 
a series of standard units, demarcated by a change in activity or a standard comment. In sequence, the confederate delivered the following script:

1. Confederate enters the room and says "Oh, I am sorry. I didn't realize that someone is in this room. Are you here for the psychology study?"

2. As the participant replies, the confederate asks "Is it over?"

i. If the participant says "yes/I think so/probably", the confederate replies "OK, good. I just need a table to sort this stack of articles. Would you mind if I sit here?"

ii. If the participants says "no/I don't think so", the confederate responds "Let me check with someone? (Then, the confederate pretends to check with the experimenter who says "yeah, that's fine, we're done."). After the experimenter responds, the confederate turns to the participant and says "I need a table to sort this stack of articles, would you mind if I sit here?”

3. Once having the permission, the confederate will sit down and say "By the way, I am one of the undergraduate researchers in this lab. So, how was the study?"

4. The confederate says "I need to alphabetize this stack of articles by the authors' last name. Can you help me out? You don't have to. No pressure”

5. If the participant agrees to help, the confederate will give the participant the stack of approximately 10 articles to sort. If the participant refuses to help, the confederate will sort the articles by him/herself. In either case, the confederate then asks the participant "Are you a psychology major?"

6. As the participant answers, the confederate says "What classes are you taking now?" 
7. As the participant responds, the confederate says "How are they going?"

The social interaction between participants and the confederate were coded by two trained undergraduate coders. One independent coder coded all 75 videos, and another coder coded $24 \%(\mathrm{n}=18)$ of randomly selected videos to establish inter-coder reliability. The author decided not to do the coding because of inconsistencies with the other coder and due to the possibility of subjective biases she may bring due to her role as the primary experimenter. The coding instructions are shown in Appendix F. Participants' behaviors were coded on the following categories or dimensions.

Agreeableness. First, the coders recorded whether the participant let the confederate into the room $(0=$ no; $1=$ yes $)$. Because all participants gave permission to the confederate to enter the room, the coders agreed perfectly on this variable $($ kappa $=1)$. Second, the amount of help the participant agreed to give to the confederate will be coded $(0=$ reject the initial request; $1=$ help upon initial request, but no further volunteering; 2 = agree to the initial request and offers additional help to the confederate after he/she complete the original request). All but one participant agreed to help the confederate. The two coders were consistent on this code (kappa = 1). Lastly, the coders determined whether the participant responded to standard question 5-7 (kappa $=1$ for each code) and recorded the duration of each comment $(\mathrm{ICC}=.85, p<.001)$. If the participants made comments related to standard question 5-7 before they were being asked, their comments would be captured in the "extra comments" categories in the "engagement" dimension. In this case, the participants were not asked the standard question(s) because the responses were already given.

Engagement. The number of times the participants made direct eye contact with the confederate (ICC $=.91, p<.001)$ and the duration of each eye contact instance $(\mathrm{ICC}=.92, p$ 
$<.001)$ were summed and recorded across the 2-minute interval. In addition, the number of times that the participant initiated new comments that were irrelevant to the confederate's questions was counted $(\mathrm{ICC}=.78, p<.001)$ and the duration was recorded $(\mathrm{ICC}=.90, p<.001)$. As mentioned above, relevant comments given before the standard questions were asked were also coded in this category. The two coders were reliable in coding whether the participants moved their chair so sit closer to the confederate (kappa =1) and whether they cleared the table to make room for the confederate (kappa $=.77)$.

Affect. Adapted from previous codes of affective behaviors (Gentzler, Wheat, Palmer \& Burwell, in press), participants' general affect expressions during the entire interaction were coded on 4-point scale, using indices from tone of voice, facial expressions, and body movements. For positive affect, the scales were described as $1=$ no positive affect expression, 2 = slight positive affect (e.g., forced smiles), 3 = moderate positive affect (e.g., at least two weak social smiles), and $4=$ intense positive affect (genuine smiles, laughing, etc.). Similarly, negative affect expressed across the entire interaction were coded for the overall global intensity, where 1 = no negative affect expression, 2 = slight, low-intense expressions of negative affect (e.g., yawning and tired voice), $3=$ moderate negative affect (e.g., sighs and slight frowning), and $4=$ intense expressions of negative affect (e.g., eye-roll or scoff, sarcasm, raised voice). The intraclass correlations of positive and negative affect were .46 and .62 respectively.

Manipulation check Two 2 (experimental conditions: positive vs. negative) X 3 (mood ratings: baseline vs. after mood induction vs. before social interaction) ANOVAs with the experimental condition as the independent variable and participants' reported mood as the dependent variable was conducted as a manipulation check to assess the effectiveness of positive and negative mood induction. The interaction between experimental conditions and mood ratings 
was significant for self-reported positive affect $\left(F=42.89, p<.001\right.$, partial $\left.\eta^{2}=.37\right)$, and negative affect $\left(F=16.84, p<.001\right.$, partial $\left.\eta^{2}=.19\right)$, indicating that the mood ratings differed across experimental conditions. See Figure $1 \mathrm{a}$ and $1 \mathrm{~b}$ for the mood ratings by conditions for positive mood and negative mood, respectively. The main effects of condition were not significant for positive mood ratings $\left(F=1.87, p=.18\right.$, partial $\left.\eta^{2}=.03\right)$ and negative mood ratings $\left(F=2.84, p=.10\right.$, partial $\left.\eta^{2}=.04\right)$. Contrast analyses showed that participants reported significantly higher levels of positive mood after positive mood induction $(M=3.08)$, compared to baseline $(M=2.89), F$ contrast $(1,37)=9.87, p<.001$, partial $\eta^{2}=.21$. However, their selfreported positive mood before social interaction $(M=2.87)$ returned to approximately baseline level $(M=2.89)$, in the positive mood condition, $F$ contrast $(1,37)=.154, p=.70$, partial $\eta^{2}=$ .001. Participants in the positive mood condition also reported less negative mood after positive mood induction $(M=1.78)$, compared to baseline, $(M=2.03), F$ contrast $(1,37)=19.21, p<$ .001 , partial $\eta^{2}=.34$. Their self-reported negative mood before social interaction $(M=1.81)$ was also significantly lower than their baseline level $(M=2.03), F$ contrast $(1,37)=12.48, p<.001$, partial $\eta^{2}=.25$

On the other hand, participants in the negative mood condition reported significantly lower levels of positive mood $(M=2.58)$ after negative mood induction, compared to baseline $(M=3.08), F$ contrast $(1,36)=53.55, p<.001$, partial $\eta^{2}=.60$. Their self-reported positive mood before social interaction $(M=2.77)$ was also significantly lower than their baseline level $(M=3.08), F$ contrast $(1,36)=37.74, p<.001$, partial $\eta^{2}=.51$. They also reported significantly high levels of negative mood after negative mood induction $(M=2.20)$, compared to baseline $(M$ $=1.95), F$ contrast $(1,36)=10.73, p<.001$, partial $\eta^{2}=.23$. However, their self-reported 
negative mood before social interaction $(M=1.96)$ returned to baseline level $(M=1.95), F$ contrast $(1,36)=.01, p=.91$, partial $\eta^{2}=.001$.

Because 3 different female and one male confederate were used and the confederates' appearance or other characteristics might influence the behaviors of the participants, a manipulation check was conducted to determine if participants' social interaction style differ by confederates. The results from the univariate ANOVA analyses revealed no main effect of confederate on all of the social interaction variables, suggesting that the participants did not behave differently based on which confederate they interacted with.

\section{Results}

\section{Preliminary analyses}

Variables of interest were screened for missing data, outliers, and violations of normality. Since mood induction was expected to have an effect on participants' self-reported mood, missing values on the mood rating scales were imputed with the corresponding group means by conditions. For example, if the rating of happy was omitted by one of the participants in the positive mood condition, this missing value would be replaced with the average rating of happy in the positive mood condition. The same replacing rule also applied to negative mood ratings. Missing values on the attachment scales were replaced with the corresponding means across conditions. There was an outlier in the baseline and post-induction valence ratings of neutral stimuli, indicating that one participant gave unusually high ratings to neutral stimuli, compared to other participants. The outliers were replaced with the group mean by conditions. With perception task accuracy, participants were generally accurate in identifying emotions. In particular, their accuracy of recognizing positive emotions (i.e., happy and surprise), anger and neutral emotion were negatively skewed. Transformations of variables did not improve the 
violation of normality issue. Therefore, the raw scores of these variables were retained for further analyses. Means and standard deviations of study variables are shown in Table 2.

Preliminary analyses with gender revealed that there was no significant gender difference in any of the perception task variables. Bivariate correlations suggested that the age of participants was negatively related to accuracy of recognizing fear $(r=-.24, p=.04)$, and positively related to perceived intensity of positive $(r=.27, p=.02)$ and negative emotions ( $r=$ $.31, p=.01)$, and valence ratings of neutral emotions $(r=.24, p=.04)$ during the emotion perception task. Examination of scatter plots suggested that these trends were not attributed to an outlier. Independent sample t-tests revealed racial differences in baseline perceived intensity of sadness $(t(73)=-2.43, p=.02)$, baseline perceived valence of neutral stimuli $(t(73)=-2.16, p$ $=.03$ ), and accuracy in recognizing negative emotions during the post mood induction emotion perception task $(t(73)=2.04, p=.05)$. These results suggested that non-Caucasian American participants perceived sadness as more intense but rated neutral stimuli as more positive at baseline, compared to Caucasian American. They were also less accurate in recognizing negative emotions during the post mood induction emotion perception task. Because the question on physical abuse was only administered to half of the participants and there were only 5 cases $(\mathrm{N}=41)$ reporting history of physical abuse, this variable was not examined.

Bivariate correlations also indicated that avoidant attachment was negatively related to accuracy of recognizing neutral stimuli $(r=-.23, p=.05)$ after mood induction. However, when the correlations were analyzed by experimental conditions, anxious attachment was positively correlated with accuracy of recognizing negative emotions $(r=.33, p=.04)$, especially fear $(r=$ $.37, p=.02)$, but avoidance attachment was unrelated to any perception task variables in the 
positive mood condition. There was no significant correlation between attachment style and perception task variables in the negative mood condition.

\section{Research question 1: Does mood influence one's perception of facial expression?}

Hypothesis 1a. A mixed-model ANOVA was used to test the hypothesis that the mood of the participants would lead to higher accuracy in identifying mood-congruent face stimuli, relative to mood-incongruent ones. The within-subjects factor was the valence of emotional stimuli (positive vs. negative). The between-subjects factor was the types of mood induction (positive vs. negative). In contrast to our expectation, the results revealed that there was no significant interaction of emotion valence by mood induction, $F(1,73)=.002, p=.96$, partial $\eta^{2}$ $=.001$. The main effect of mood induction was also non-significant, $F(1,73)=.006, p=.94$, partial $\eta^{2}=.001$. However, the main effect of emotion valence was significant, $F(1,73)=$ 132.09, $p<.001$, partial $\eta^{2}=.64$ ), such that participants were more accurate in recognizing positive emotions $(M=.97 ; S D=.05)$ than negative emotions $(M=.77 ; S D=.14)$, regardless of mood induction. Means and standard deviations of the measures were shown in Table 2.

Hypothesis 1b. We performed a mixed model ANOVA to examine mood effects on perceived intensity of emotions. We hypothesize that people would perceive mood-congruent expressions as more intense and mood-incongruent expressions as less intense. The withinsubject factor was the valence of emotion displayed by the face stimuli (positive vs. negative). The between-subject factor was types of mood induction (positive vs. negative). Results showed that there was neither significant interaction effect of emotion valence by mood induction, $F(1$, $73)=.10, p=.75$, partial $\eta^{2}=.001$, nor main effect of mood induction, $F(1,73)=.29, p=.59$, partial $\eta^{2}=.001$. Nonetheless, there was a significant main effect of emotion valence, $F(1,73)=$ $84.51, p<.001$, partial $\eta^{2}=.54$, such that participants generally perceived positive emotions $(M$ 
$=6.47 ; S D=1.30)$ as more intense than negative emotions $(M=5.47 ; S D=1.52)$. Means and standard deviations of the measures were shown in Table 2. Summary of the mixed-model ANOVA analyses was presented in Table 3.

Hypothesis 1c. To test the hypothesis that emotionally-aroused participants would attribute their own mood or similar-valenced affects to neutral face stimuli after mood induction, we run an ANOVA to compare participants' accuracy in identifying neutral faces and perceived valence of neutral stimuli from the baseline test and the experimental test. Results revealed a non-significant trend that the participants were less accurate in recognizing neutral emotions after mood induction, $F(1,73)=.20, p=.66$, partial $\eta^{2}=.001\left(M_{\text {baseline accuracy }}=.88 ; S D=.20 ; M\right.$ post mood induction accuracy $=.86 ; S D=.15)$. However, there was a significant main effect of condition, $F(1,73)=5.65, p=.02$, partial $\eta^{2}=.07$, indicating that people in the positive mood condition were more accurate in recognizing neutral stimuli $\left(M_{\text {positive condition }}=.91 ; S D=.13 ; M_{\text {negative condition }}\right.$ $=.83 ; S D=.20)$. With regard to perceived valence of neutral stimuli, the results suggested that participants rated the valence of neutral face as more negative after mood induction, $F(1,73)$ $=21.52, p<.001$, partial $\eta^{2}=.23\left(M_{\text {basline valence }}=.42 ; S D=1.42 ; M_{\text {post mood induction valence }}=-.52 ; S D\right.$ $=1.13)$, regardless of the experimental conditions (See Table 4).

\section{Research question 2: Does biased perception of facial expression affect social interaction?}

Concerning data aggregation for the social interaction task, there were 5 categorical codes in the agreeableness scale: whether participants let the confederate in, the extent to which they help the confederate, and whether they responded to each of the 3 standard questions. Almost all participants helped and responded to the confederate to some extent. In some cases, the confederate did not deliver all the standard questions because the participants already addressed a later question in their responses to the previous standard question(s), making the 
standard question codes invalid. Due to the lack of variability and the associated validity issues in the agreeableness codes, they were not analyzed further. Instead, the duration of participants' responses to the standard questions were summed and used as the index of agreeableness in further analysis.

For the similar reasons, the move-chair and the clear-table codes would be excluded in further analyses. Only 2 participants moved their chair, resulting in lack of variability in this code. Although there were 28 participants $(37.3 \%)$ who cleared the table to make room for the confederate, the majority of the participants did not have their personal belongings on the table so the code was invalid in a sense that it did not apply to some of the participants. Therefore, the count and duration of eye contact and additional comments were the only variables retained as indices of engagement. These were analyzed as separate variables because the variables were only moderately correlated at the most (range -.23 to .78; see Table 5).

The count and duration of participants' response to standard questions, their eye contact with the confederate, and initiation of additional comments were positively skewed. These variables were recomputed with square-root transformation for further analyses. Negative affect was also positively skewed because only four participants were coded as having a negative affect score higher than 2 (i.e., slight, low-intense expressions of negative affect). Despite the lack of variability in this variable, it was retained in further analyses because it reflected the affective behaviors of the participants.

Hypothesis 2a. Bivariate correlations suggested that age, gender, race and attachment style were unrelated to any of the social interaction variables. Therefore, they were not included as controlling variables in the ANOVA analyses conducted to test the hypothesis that participants in the positive mood condition would show more initiative behaviors, make more 
eye contact with the confederate, and exhibit more positive affect during the social interaction, compared to those in the negative mood condition. The results revealed a significant main effect of condition on positive affect, $F(1,73)=5.13, p=.03$, partial $\eta^{2}=.07$ and total number of additional comments, $F(1,73)=5.73, p=.02$, partial $\eta^{2}=.07$. Specifically, participants in the positive mood condition exhibited more positive affect, but initiated less additional comments than participants in the negative mood condition. There was also a nonsignificant trend that those in the positive mood condition gave lengthier responses to the standard questions, $F(1,73)=$ $3.57, p=.06$, partial $\eta^{2}=.05$. No other significant differences were found. Descriptive statistics for the retained social interaction variables are shown in Table 6 .

Hypothesis $\mathbf{2 b}$. To test the moderation hypothesis that those who rated mood-congruent faces as more intense would be more susceptible to the mood effect on social interaction, a series of linear regression analyses were conducted on the social interaction variables. Participants' ratings of perceived intensity of positive and negative emotions were centered. Two interaction terms were created for experimental conditions by perceived intensity of positive and negative emotions, respectively. Summaries of the analyses are shown in Table 7 and Table 8. Specifically, no significant interaction was found. However, perceived intensity of negative emotions predicted the total number and duration of eye contact. Those who perceived negative emotions as more intense made more eye contact with the confederate for a longer duration of time. There was no significant main effect of perceived intensity of positive emotions (happy and/or surprise). Follow up linear regression analyses were performed to delineate any emotionspecific effect of perceived intensity of anger, sadness and fear on eye contact during social interaction. The results revealed that those who perceived fear as more intense tended to make more eye contact with the confederate, $B=.11, S E=.05, p=.02$, for a longer duration, $B=.26$, 
$S E=.10, p=.01$. Perceived intensity of anger only predicted more eye contact, $B=.11, S E=.05$, $p=.05$, but were unrelated to duration of eye contact. No significant result was found with perceived intensity of sadness.

As we did not find significant association between experimental condition and perceived intensity of emotions, one of the essential conditions for testing the mediation model was not met. Therefore, the mediation analysis was not performed.

\section{Exploratory analyses}

Because the perception task accuracy variables were highly skewed, we dichotomized all the accuracy variables $(1=$ all correct; $0=$ get one or more questions wrong $)$ and performed ChiSquare analyses to see if participants' accuracy of recognizing emotions differ by experimental conditions. No significant results were found from these tests. Therefore, we decided to report on the mixed-model ANOVA results, using the untransformed, continuous variables of perception task accuracy.

Preliminary analyses revealed age differences in perceived intensity of emotions (both positive and negative) and race differences in accuracy of recognizing negative emotions. Therefore, additional mix-model ANOVA analyses were performed with age and race as control variables. Race was dichotomized ( $1=$ Caucasian American; $2=$ non-Caucasian American). The results revealed a significant valence by race interaction on perception task accuracy, $F(1,70)=$ 4.42, $p=.04$, partial $\eta^{2}=.06$. Non-Caucasian American participants performed poorer in recognizing negative emotions than positive emotions, compared to their Caucasian American counterparts (See Figure 2). In addition, there was a nonsignificant trend that, after controlling for age and race, participants in the negative mood condition perceived neutral stimuli as more negative after the mood induction, compared to those in the positive mood condition, $F(1,70)=$ 
$3.70, p=.06$, partial $\eta^{2}=.05$ (See Figure 3$)$. No other interaction was significant. When

attachment styles were included in the models, the patterns of results were similar. Therefore, we chose to report the statistics from the mixed-model ANOVA analyses with only age and race as covariate.

For exploratory purpose, the effect of baseline mood on emotion perception at baseline was examined using linear regression analyses with baseline reported positive and negative mood as predictor variables, controlling for age and race. Baseline recognition accuracy and perceived intensity of the emotional stimuli were included as the outcome variables. It was shown that baseline negative mood predicted lower accuracy of recognizing neutral stimuli, over and above the effect of age and race, $B=-.15, S E=.05, p=.01$. The effects of self-reported mood on emotion perception after mood induction were also examined, controlling for age and race. The results revealed that self-reported positive mood after mood induction predicted higher accuracy of recognizing neutral stimuli, above and beyond the effect of age and race, $B=.09, S E$ $=.04, p=.03$. Finally, self-reported mood assessed before the social interaction tasks were also examined in relation to the social interaction variables in a series of linear regression analyses, controlling for age and race. It was found that self-reported positive mood before the social interaction task predicted more eye contact incidences with the confederate, $B=.40, S E=.17, p$ $=.02$. No other significant result was found in these exploratory analyses.

\section{Discussion}

\section{Mood effect on recognition accuracy of emotions}

The first goal of the study was to investigate the effects of different mood states (positive and negative) on young adults' ability to correctly recognize others' emotions and their perceived intensity of those emotions. We hypothesized a mood-congruity effect on emotion 
perception, such that participants would be more accurate in recognizing mood-congruent emotions and would rate them as more intense than mood-incongruent ones (Hypothesis 1a and 1b). The overall findings revealed no significant differences in perception task accuracy and perceived intensity of positive and negative emotions across the two experimental conditions. Although our results did not support the mood-congruent effect on emotion perception, our findings were consistent with past literature in two aspects. First, in line with past research on perception of emotional expressions (e.g., Lee et al., 2008; Schmid \& Mast, 2010), there was no evidence for an overall performance decrement among the current sample of healthy young adult in the negative mood condition, suggesting that negative mood did not impair general perception of emotional expressions in healthy individuals as it did in depressed individuals (e.g., Persad \& Polivy, 1993; Surguladze et al., 2004). Second, results were also consistent with previous research in that positive emotions were easier to recognize correctly, than negative emotions (Ellis et al., 1997; Surguladze et al., 2004; Trevisani et al., 2008).

There were several factors that could explain our null findings on emotion recognition accuracy. For example, there was ceiling effects in emotion recognition performance of happiness, surprise and anger. The overall rates of accuracy were $99.1 \%, 94.4 \%$, and $94.9 \%$, respectively. The high rates of accuracy and the lack of variability in positive emotion recognition performance reduced the sensitivity of our experiment in finding a mood-congruity effect in emotion perception accuracy.

The presentation time $(800 \mathrm{~ms})$ of each emotional stimulus in the present study could also account for the high recognition performance in our participants. Past research indicated that healthy participants were able to correctly identify facial expressions of emotions presented for duration as brief as $100 \mathrm{~ms}$ to $200 \mathrm{~ms}$ (Sato, Kochiyama, Yoshikawa, \& Matsumura, 2001; 
Surguladze et al, 2004). The presentation duration of $800 \mathrm{~ms}$ in the present study might make the recognition task too easy for our participants, although it gave them enough time to make judgment about perceived intensity of the emotions.

\section{Mood effect on perceived intensity of emotions}

To our knowledge, little research has focused on the effect of mood on perceived intensity of emotions (for exception, see Schiffenbauer, 1974). The present study addressed this gap in the literature. However, the findings did not support the intensity hypothesis that participants would perceive mood-congruent emotions as more intense and mood-incongruent emotions as less intense. Instead, our results suggested that young adults perceived positive emotions as more intense than negative emotions, regardless of their current mood state. One explanation for these results could be that facial features indicative of positive emotions (happy and surprise) are generally more salient than those that characterize negative emotions (Calvo \& Nummenmaa, 2011). Salient facial features, such as an upturned mouth (as in a happy expression) might have appeared more intense to the participants. In support of this interpretation, research on infant smiling provides empirical support for a positive association between young adults' perceived intensity of infant smiles and the degree of smile strength and mouth opening on an infant's face (Messinger, Cassel, Acosta, Ambadar, \& Cohn, 2008), suggesting that salience of facial features affects perceived intensity of emotions. Thus, because participants generally tended to perceive positive emotions as more intense than negative emotions due to the salience of facial features of positive emotions, this tendency may have washed out the hypothesized mood-congruity effect on perceived intensity of emotions. 


\section{Mood-congruity effect on emotion perception}

In contrast to previous studies with young adults, the present study failed to show a direct link between mood and emotion perception. Our results did not provide evidence for the moodcongruity effect reported in past literature (e.g., Lee et al., 2008; Schmid \& Mast, 2010) as participants in the positive mood and negative mood conditions did not differ significantly in their emotion recognition accuracy and perceived intensity of emotions. There are at least two possible explanations for our nonsignificant findings. First of all, the present study did not manipulate the intensity of the facial expressions depicted in our stimuli. The Ekman photos depicted prototypical expressions of basic emotions. The posers were instructed to activate certain facial muscles associated with various emotional expressions in a way that makes the expressions as discernible as possible (Ekman \& Friesen, 1976). Therefore, the facial expressions in the Ekman face database tend to be of high intensity. Past research has shown that high intensity facial emotions were easier to correctly identify than low intensity facial expressions (Schmid \& Mast, 2010). Because the stimuli in the present study were relatively easier to recognize, the resulting ceiling effects may have reduced the sensitivity of our experiment. Future research may consider varying the intensity of the face stimuli using face morphing software (e.g., Niedenthal et al., 2002; Schmid \& Mast, 2010).

In addition, the use of a wide range of facial expressions (happy, sad, neutral, anger, surprise, and fear) may have washed out the expected mood-congruity effects. Likewise, Schmid and colleagues (2011) used 4 different types of emotional facial expressions and did not find a mood-congruity effect on emotion recognition accuracy in their study. On the other hand, Schmid and Mast (2010) only used happy and sad expressions and reported that sad participants 
recognized sad facial expressions better than happy ones, indicating a mood-congruity effect in the negative mood condition.

\section{Mood and perception of neutral expressions}

Concerning the perception of neutral stimuli, emotionally-aroused participants did not perform worse in recognizing neutral expressions after mood induction, although there was a trend. Consistent with Surguladze et al. (2004), we also found that participants in the negative mood condition were more likely to misidentify neutral expressions as emotional, compared to those in the positive mood condition. This perceptual bias reflected a tendency toward labeling neutral expressions as negative emotions rather than positive ones. Additionally, participants tended to perceive neutral face as more negative when they were emotionally-aroused (after mood induction). These results suggest that being emotionally-aroused, especially in a negative mood, may make people more susceptible to misattribution of neutral expressions as emotional. Such tendencies could be problematic if an agitated person attributes his/her own negative emotions to a rather calm individual and therefore acts aggressively toward that individual, leading to tension between the two.

\section{The roles of mood and emotion perception in social interaction}

Given the importance of emotion perception in guiding our social behaviors (Keltner \& Kring, 1998), the second goal of the present study was to examine if the perception of other's emotions plays a role in how mood influences the subsequent behaviors of the perceivers. We hypothesized that participants in the positive mood condition would be more agreeable to help and more engaging in the social conversation, and show more positive affect but less negative affect during the social interaction with a stranger, compared to those in the negative mood condition. We also expected that those who rate mood-congruent stimuli as more intense would 
be more susceptible to the mood effect on social interaction. The results provided some support that the mood states of the participants impacted certain aspects of their social interaction. More specifically, those who were in the positive mood condition exhibited more positive affect, although they also initiated fewer additional comments. One explanation could be that these individuals tended to give lengthier responses to the standard questions, which left them with little time to initiate new comments that were irrelevant to the standard questions. These findings are in line with past research that suggests positive mood may activate behaviors with a positive valence (Batson et al., 1979; Isen, 1970). However, contrast to these previous studies, we found that participants in the present study were equally likely to offer help to the confederate, regardless of their mood states. Such discrepancy could be attributed to the methodological difference between the present study and the previous ones. In this study, the participants were explicitly asked by the confederate to help with a simple task, whereas in the past studies, participants were given opportunity to help by putting money in a donation box in the experiment room (Isen, 1970) or intervening a staged non-emergency situation (Batson et al., 1979). Therefore, our participants might be more obligated to help due to social desirability, even when they were in a relatively negative mood. Therefore, the study could be improved by using a less explicit helping task that requires more initiative from the participants (e.g., putting money in a donation box or returning a found electronic device to the experimenter).

In addition, we did not find support for the moderating effect of emotion perception on mood and social interaction, suggesting that the condition effect was not dependent on participants' emotion perception. However, there was evidence that perceived intensity of negative emotions was predictive of the amount and duration of the participants' direct eye contact during social interaction. More precisely, those who perceived fearful expressions as 
more intense tended to maintain more eye contacts with the confederate for a longer duration of time. This finding fit with previous studies that fear-prone individuals show heightened unconscious vigilance to social and emotional cues when they are emotionally-aroused (Nidenthal, Brauer, Robin \& Innes-Ker, 2002; Putman, Hermans, \& Honk, 2006). This vigilance may reflect the defensiveness of fear-prone individuals to detect potential threats/challenges in their environment so as to prepare themselves to deal with any uncertainty (Holbrook, Sousa, \& Hahn-Holbrook, 2001). In this sense, those who perceived fearful expression as more intense in the present study might be prone to the vigilance associated with fear arousal, and thus, tended to maintain more eye contacts with the confederate for a longer time in search for more social cues to make sense of the uncertain situation. On the other hand, perceived intensity of anger was also predictive of more eye contact with the confederate in the current sample. Limited research has shown that anger arousal might prime a sense of dominance in human, leading to more gaze behaviors in face-to-face confrontations (Ellsworth \& Carlsmith, 1973; Terburg, Hooiveld, Aarts, Leon Kenemans, \& van Honk, 2011). In the context of the present study, those who perceived anger as more intense might be prone to anger arousal, and thus, make more eye contact with the confederate as a way to express their dominance in the face-to-face social interaction.

\section{Discussion of the exploratory findings}

In the exploratory analyses, the results revealed that older participants generally perceived positive and negative emotions as more intense, compared to younger participants. Age differences have been found in a sample of children and adolescents, with young adolescents perceived negative emotions as more intense, compared to pre-adolescent children (van Beek \& Dubas, 2008). However, the corresponding finding in the present study should be 
interpreted with caution because van Beek and Dubas (2008) reported age differences in perceived intensity of emotional stimuli across two developmental periods, namely late childhood and early adolescence, during which there are important improvements in emotional knowledge and experiences. Therefore, adolescents may perceive others' emotional expressions as more intense because they become increasingly aware of the fact that people may suppress or hide their emotions so the actual intensity of other's emotions may be higher than what are expressed. Because we did not specifically recruit participants from different age groups, replications of the current finding are needed to determine whether the age differences found in the present study reflect the normative development in emotional understanding or simply experimental artifact.

In addition to the age differences, there was also a valence by race interaction effect on recognition accuracy of emotional expressions in the current sample. In other words, Caucasian and non-Caucasian participants performed comparably well in recognizing positive emotions. However, non-Caucasian participants were less accurate in recognizing negative emotions, compared to their Caucasian counterparts. Such difference can be attributed to an in-group advantage in identifying emotions among the Caucasian participants because the experimental stimuli depicted Caucasian faces. In support of this explanation, past research has found that perceivers were less accurate in recognizing faces and emotional expressions displayed by members of a different racial group, but made fewer errors when they interpret facial expressions of members of their own racial group (Johnson \& Fredrickson, 2005; Wickline, Bailey, \& Nowicki, 2009). Due to the ceiling effect in recognition accuracy of positive emotions in the current sample, non-Caucasian and Caucasian performed almost equally well in identifying positive emotions. However, Caucasian participants seemed to benefit from the in-group 
advantage in recognizing negative emotions probably because they were more familiar to the emotional expressions of members of their own race.

\section{Limitations and future directions}

Several limitations of the present study are worth noting. First of all, although the intended effects of mood manipulation were statistically significant, the some of these effects were of small magnitude (partial $\eta^{2}$ ranged from .19 to .60 ). Furthermore, the induced mood did not last. The present study used event recall as the mood manipulation method in an attempt to induce more intense affective reactions because participants might easily relate to personallymeaningful events. Given the patterns of mood change in the present study, it is plausible that the participants might have employed regulatory strategies to down-regulate their affective states so the induced mood did not last. In future studies, researchers can play emotional music in the background while the participants are completing the experimental task(s) to maintain their affective states after the mood manipulation. Second, the study was underpowered to detect small effects because of the relatively small sample size. Third, due to the use of prototypical emotional face stimuli, the ceiling effect in perception task accuracy reduced the sensitivity in detecting the mood-congruity effect in emotion perception. Fourth, the use of a wide range of emotional stimuli might have further washed out the mood-congruity effect. Therefore, it is plausible that with a larger sample and better control of the physical properties of the face stimuli, we may be able to find the expected mood-congruity effect in recognition accuracy and perceived intensity of emotions. Fifth, the inter-rater reliability of the affect codes in the social interaction task was low. But the coding discrepancies were discussed and addressed in the final

analyses of the social interaction data. Lastly, there was little variability in the helping behaviors and negative affect during the social interaction task. It could be that the participants agreed to 
help and attempted to suppress their negative affect because of social desirability, regardless of their current mood states.

In sum, the present study did not find mood-congruity effects in recognition accuracy and perceived intensity of emotional expressions. However, it contributed to our understanding of how moods influence perception of neutral expressions. In particular, negative mood seems to impair recognition of neutral stimuli in the current sample, suggesting the people may be prone to misattributing their negative emotions to neutral expressions. Emotionally-aroused individuals also tended to perceived neutral expressions as more negative, regardless of their mood states. Such a tendency may influence the subsequent behaviors of the perceivers as they attribute their own emotions to a rather neutral expressor. Although the results from the present study did not support the moderating or mediating effects of emotion perception on how mood influences the social behaviors of the perceivers, future research may find results in line with our hypotheses with improved methodologies such as a large sample size, the use of morphed face stimuli (to make the perception task more challenging yet sensitive), and the implementation of a social interaction task that is less susceptible to social desirability effects. 


\section{References}

Batson, C. (1979). Generality of the 'glow of goodwill': Effects of mood on helping and information acquisition. Social Psychology Quarterly, 42(2), 176-179.

Bouhuys, A. L., Bloem, G. M., \& Groothuis, T. G. (1995). Induction of depressed and elated mood by music influences the perception of facial emotional expressions in healthy subjects. Journal of Affective Disorders, 33(4), 215-226.

Bouhuys, A. L., Geerts, E., \& Gordijn, M. M. (1999). Depressed patients' perceptions of facial emotions in depressed and remitted states are associated with relapse: A longitudinal study. Journal of Nervous and Mental Disease, 187(10), 595-602.

Bower, G. H. (1981). Mood and memory. American Psychologist, 36(2), 129-148.

Calvo, M. G., \& Nummenmaa, L. (2011). Time course of discrimination between emotional facial expressions: The role of visual saliency. Vision Research, 51(15), 1751-1759.

Cavanagh, J., \& Geisler, M. W. (2006). Mood effects on the ERP processing of emotional intensity in faces: A P3 investigation with depressed students. International Journal of Psychophysiology, 60(1), 27-33.

Chepenik, L. G., Cornew, L. A., \& Farah, M. J. (2007). The influence of sad mood on cognition. Emotion, 7(4), 802-811.

Cohen, D., Nisbett, R. E., Bowdle, B. F., \& Schwarz, N. (1996). Insult, aggression, and the southern culture of honor: An 'experimental ethnography.'. Journal of Personality and Social Psychology, 70(5), 945-960.

Coles, M. E., Heimberg, R. G., \& Schofield, C. A. (2008). Interpretation of facial expressions and social anxiety: Specificity and source of biases. Cognition and Emotion, 22(6), 1159- 1173. 
Cooley, E. L., \& Nowicki, S. (1989). Discrimination of facial expressions of emotion by depressed subjects. Genetic, Social, and General Psychology Monographs, 115(4), 449465.

Ekman, P. (1993). Facial Expression and Emotion. American Psychologist. 48 (4), 384-392.

Ekman, P., \& Friesen, W.V. (1976). Pictures offacial affect. Palo Alto, CA: Consulting Psychologist Press.

Ekman, P., Sorenson, E. R., Friesen, W. V. (1969). Pan-cultural elements in facial displays of emotion. Science, 164 (3875), 86-88.

Ellis, C. R., Lindstrom, K. L., Villani, T. M., Singh, N. N., Best, A. M., Winton, A. W., \& ... Leung, J. P. (1997). Recognition of facial expressions of emotion by children with emotional and behavioral disorders. Journal of Child and Family Studies, 6(4), 453-470.

Ellsworth, P., \& Carlsmith, J. (1973). Eye contact and gaze aversion in an aggressive encounter. Journal of Personality and Social Psychology, 28(2), 280-292.

Engelberg, E., \& Sjöberg, L. (2004). Emotional intelligence, affect intensity, and social adjustment. Personality and Individual Differences, 37(3), 533-542.

Faul, F., Erdfelder, E., Lang, A.-G., \& Bucher, A. (2007). G*Power 3: A flexible statistical power analysis program for the social, behavioral, and biomedical sciences. Behavior Research Methods, 39, 175-191.

Fischer, A. H., \& van Kleef, G. A. (2010). Where have all the people gone? A plea for including social interaction in emotion research. Emotion Review, 2(3), 208-211.

Forgas, J. P. (1995). Mood and judgment: The affect infusion model (AIM). Psychological Bulletin, 117(1), 39-66. 
Forgas, J. P., \& Bower, G. H. (1987). Mood effects on person-perception judgments. Journal of Personality and Social Psychology, 53(1), 53-60.

Fraley, R., Niedenthal, P. M., Marks, M., Brumbaugh, C., \& Vicary, A. (2006). Adult attachment and the perception of emotional expressions: Probing the hyperactivating strategies underlying anxious attachment. Journal of Personality, 74(4), 1163-1190.

Fraley, R. C., Waller, N. G., \& Brennan, K. A. (2000). An item-response theory analysis of selfreport measures of adult attachment. Journal of Personality and Social Psychology, 78, $350-365$.

Fridlund, A. J. (1994). Human facial expression: An evolutionary view. San Diego, CA US: Academic Press.

Gentzler, A. L., Wheat, A. L., Palmer, C. A., \& Burwell, R. A. (in press). Children's responses to cognitive challenge and links to self-reported rumination. Cognition and Emotion.

Gollan, J. K., McCloskey, M., Hoxha, D., \& Coccaro, E. F. (2010). How do depressed and healthy adults interpret nuanced facial expressions?. Journal of Abnormal Psychology, 119(4), 804-810.

Hall, J. A., \& Matsumoto, D. (2004). Gender differences in judgments of multiple emotions from facial expressions. Emotion, 4(2), 201-206.

Hoffmann, H., Kessler, H., Eppel, T., Rukavina, S., \& Traue, H. C. (2010). Expression intensity, gender and facial emotion recognition: Women recognize only subtle facial emotions better than men. Acta Psychologica, 135(3), 278-283.

Holbrook, C., Sousa, P., \& Hahn-Holbrook, J. (2011). Unconscious vigilance: Worldview defense without adaptations for terror, coalition, or uncertainty management. Journal of Personality and Social Psychology, 101(3), 451-466. 
Innes-Ker, А., \& Niedenthal, P. M. (2002). Emotion concepts and emotional states in social judgment and categorization. Journal of Personality and Social Psychology, 83(4), 804-816.

Irtel, H. (2007). PXLab: The Psychological Experiments Laboratory [online]. Version 2.1.11. Mannheim (Germany): University of Mannheim. [cited 6 March 2011]. Available from <http://www.pxlab.de>.

Isen, A. M. (1970). Success, failure, attention, and reaction to others: The warm glow of success. Journal of Personality and Social Psychology, 15(4), 294-301.

Ishii, K., Miyamoto, Y., Niedenthal, P., \& Mayama, K. (2011). When your smile fades away: cultural differences in sensitivity to the disappearance of smiles. Social Psychological and Personality Science, 000(00), 1-7.

Izard, C. E. (1971). The face of emotion. East Norwalk. CT: Appleton-Century-Crofts.

Johnson, K. J., \& Fredrickson, B. L. (2005). 'We all look the same to me': Positive emotions eliminate the own-race bias in face recognition. Psychological Science, 16(11), 875-881.

Keltner, D., Ellsworth, P. C., \& Edwards, K. (1993). Beyond simple pessimism: Effects of sadness and anger on social perception. Journal of Personality and Social Psychology, $64,740-752$.

Keltner, D., \& Kring, A. M. (1998). Emotion, social function, and psychopathology. Review of General Psychology, 2(3), 320-342.

Kokkonen, M., \& Pulkkinen, L. (2001). Examination of the paths between personality, current mood, its evaluation, and emotion regulation. European Journal of Personality, $15,83-104$. 
Lee, T. C., Ng, E. H., Tang, S. W., \& Chan, C. H. (2008). Effects of sad mood on facial emotion recognition in Chinese people. Psychiatry Research, 159(1-2), 37-43.

Lembke, A., \& Ketter, T. A. (2002). Impaired recognition of facial emotion in mania. The American Journal of Psychiatry, 159(2), 302-304.

Lennox, B. R., Jacob, R. R., Calder, A. J., Lupson, V. V., \& Bullmore, E. T. (2004). Behavioural and neurocognitive responses to sad facial affect are attenuated in patients with mania. Psychological Medicine: A Journal of Research in Psychiatry and the Allied Sciences, 34(5), 795-802.

Lerner, J. S., \& Keltner, D. (2000). Beyond valence: Toward a model of emotion-specific influences on judgement and choice. Cognition and Emotion, 14(4), 473-493.

Lerner, J., \& Keltner, D. (2001). Fear, anger and risk. Journal of Personality and Social Psychology, 81, 146-159.

Leppänen, J. M., \& Hietanen, J. K. (2001). Emotion recognition and social adjustment in school-aged girls and boys. Scandinavian Journal of Psychology, 42(5), 429-435.

Masten, C. L., Guyer, A. E., Hodgdon, H. B., McClure, E. B., Charney, D. S., Ernst, M.,... \& Monk, C. S. (2008). Recognition of facial emotions among maltreated children with high rates of post-traumatic stress disorder. Child Abuse \& Neglect, 32(1), 139-153.

Manstead, A. R., \& Fischer, A. H. (2001). Social appraisal: The social world as object of and influence on appraisal processes. In K. R. Scherer, A. Schorr, T. Johnstone, K. R. Scherer, A. Schorr, T. Johnstone (Eds.), Appraisal processes in emotion: Theory, methods, research (pp. 221-232). New York, NY US: Oxford University Press.

Marsh, A. A., Ambady, N., \& Kleck, R. E. (2005). The effects of fear and anger facial expressions on approach- and avoidance-related behaviors. Emotion, 5(1), 199-124. 
Mayer, J. D., Allen, J. P., \& Beauregard, K. (1995). Mood inductions for four specific moods: A procedure employing guided imagery vignettes with music. Journal of Mental Imagery, 19(1-2), 151-159.

Mayer, J. D., \& Gaschke, Y. N. (1988). The experience and meta-experience of mood. Journal of Personality and Social Psychology, 55, 102-111.

Messinger, D. S., Cassel, T. D., Acosta, S. I., Ambadar, Z., \& Cohn, J. F. (2008). Infant smiling dynamics and perceived positive emotion. Journal of Nonverbal Behavior, 32(3), 133155.

Montagne, B., Kessels, R. C., Frigerio, E., de Haan, E. F., \& Perrett, D. I. (2005). Sex differences in the perception of affective facial expressions: Do men really lack emotional sensitivity?. Cognitive Processing, 6(2), 136-141.

Niedenthal, P. M., Brauer, M., Robin, L., \& Innes-Ker, Å. H. (2002). Adult attachment and the perception of facial expression of emotion. Journal of Personality and Social Psychology, 82(3), 419-433.

Niedenthal, P. M., \& Halberstadt, J. B. (2003). Top-down influences in social perception. In W. Stroebe, M. Hewstone, W. Stroebe, M. Hewstone (Eds.), European review of social psychology, Vol 14 (pp. 49-76). Hove England: Psychology Press/Taylor \& Francis (UK).

Niedenthal, P. M., \& Setterlund, M. B. (1994). Emotion congruence in perception. Personality and Social Psychology Bulletin, 20(4), 401-411.

Norman, D. A., \& Rumelhart, D. E. (1975). Memory and knowledge. In D. A. Norman, D. E. Rumelhart, \& the LNR Research Group (Eds.), Explorations in cognition. San Francisco: Freeman. 
Persad, S. M., \& Polivy, J. (1993). Differences between depressed and nondepressed individuals in the recognition of and response to facial emotional cues. Journal of Abnormal Psychology, 102(3), 358-368.

Pollak, S. D., Cicchetti, D., Hornung, K., \& Reed, A. (2000). Recognizing emotion in faces: Developmental effects of child abuse and neglect. Developmental Psychology, 36(5), 679-688.

Pollak, S.D., \& Kistler, D.J. (2002). Early experience is associated with the development of categorical representations for facial expressions of emotion. Proceedings of the National Academy of Sciences, USA, 99, 9072-9076.

Putman, P., Hermans, E., \& van Honk, J. (2006). Anxiety meets fear in perception of dynamic expressive gaze. Emotion, 6(1), 94-102.

Richards, A., French, C. C., Calder, A. J., Webb, B., Fox, R., \& Young, A. W. (2002). Anxiety-related bias in the classification of emotionally ambiguous facial expressions. Emotion, 2(3), 273-287.

Russell, J. A. (2003). Core affect and the psychological construction of emotion. Psychological Review, 110(1), 145-172.

Sato, W., Kochiyama, T., Yoshikawa, S., \& Matsumura, M. (2001). Emotional expression boosts early visual processing of the face: ERP recording and its decomposition by independent component analysis. Neuroreport: For Rapid Communication of Neuroscience Research, 12(4), 709-714.

Schachter, S., \& Singer, J. (1962). Cognitive, social, and physiological determinants of emotional state. Psychological Review, 69(5), 379-399. 
Schiffenbauer, A. (1974). Effect of observer's emotional state on judgments of the emotional state of others. Journal of Personality and Social Psychology, 30(1), 31-35.

Schmid, P., \& Mast, M. (2010). Mood effects on emotion recognition. Motivation and Emotion, 34(3), 288-292.

Schofield, C. A., Coles, M. E., \& Gibb, B. E. (2007). Social anxiety and interpretation biases for facial displays of emotion: Emotion detection and ratings of social cost. Behavior Research and Therapy, 45(12), 2950-2963.

Schwarz, N. (1990). Feelings as information: Informational and motivational functions of affective states. In E. Higgins, R. M. Sorrentino, E. Higgins, R. M. Sorrentino (Eds.), Handbook of motivation and cognition: Foundations of social behavior, Vol. 2 (pp. 527561). New York, NY US: Guilford Press.

Schwarz, N., \& Clore, G. L. (1983). Mood, misattribution, and judgments of well-being: Informative and directive functions of affective states. Journal of Personality and Social Psychology, 45(3), 513-523.

Surguladze, S. A., Young, A. W., Senior, C., Brébion, G., Travis, M. J., \& Phillips, M. L. (2004). Recognition accuracy and response bias to happy and sad facial expressions in patients with major depression. Neuropsychology, 18(2), 212-218.

Terburg, D., Hooiveld, N., Aarts, H., Leon Kenemans, J. J., \& van Honk, J. (2011). Eye tracking unconscious face-to-face confrontations: Dominance motives prolong gaze to masked angry faces. Psychological Science, 22(3), 314-319.

Thomas, L. A., De Bellis, M. D., Graham, R., \& LaBar, K. S. (2007). Development of emotional facial recognition in late childhood and adolescence. Developmental Science, 10(5), 547-558. 
Trevisani, D. P., Johnson, S. L., \& Carver, C. S. (2008). Positive mood induction and facial affect recognition among students at risk for mania. Cognitive Therapy and Research, 32(5), 639-650.

van Beek, Y., \& Dubas, J. (2008). Age and gender differences in decoding basic and non-basic facial expressions in late childhood and early adolescence. Journal of Nonverbal Behavior, 32(1), 37-52.

van Der Veen, F. M., Evers, E. T., Deutz, N. P., \& Schmitt, J. J. (2007). Effects of acute tryptophan depletion on mood and facial emotion perception related brain activation and performance in healthy women with and without a family history of depression. Neuropsychopharmacology, 32(1), 216-224.

Waugh, C. E., \& Fredrickson, B. L. (2006). Nice to know you: Positive emotions, selfother overlap, and complex understanding in the formation of a new relationship. The Journal of Positive Psychology, 1(2), 93-106.

Wickline, V. B., Bailey, W., \& Nowicki, S. (2009). Cultural in-group advantage: Emotion recognition in African American and European American faces and voices. The Journal of Genetic Psychology: Research and Theory on Human Development, 170(1), 5-29. 
Table 1

Demographic Information of Participants

\begin{tabular}{|c|c|c|c|c|c|c|}
\hline Variables & $\begin{array}{l}\text { Positive } \\
\text { induction } \\
(\%)\end{array}$ & $\mathrm{n}$ & $\begin{array}{c}\text { Negative } \\
\text { induction } \\
(\%)\end{array}$ & $\mathrm{n}$ & $\begin{array}{c}\text { Total } \\
(\%)\end{array}$ & $\mathrm{n}$ \\
\hline $\begin{array}{l}\text { Number of } \\
\text { participants }\end{array}$ & 50.7 & 38 & 49.3 & 37 & & \\
\hline \multicolumn{7}{|l|}{ Gender } \\
\hline Male & 42.1 & 16 & 27 & 10 & 34.7 & 26 \\
\hline Female & 57.9 & 22 & 73 & 27 & 65.3 & 49 \\
\hline \multicolumn{7}{|l|}{ Race } \\
\hline Caucasian & 81.6 & 31 & 83.8 & 31 & 82.6 & 62 \\
\hline African American & 7.9 & 3 & 8.1 & 3 & 8 & 6 \\
\hline Hispanic American & 2.6 & 1 & 2.7 & 1 & 2.7 & 2 \\
\hline Asian American & 2.6 & 1 & 2.7 & 1 & 2.7 & 2 \\
\hline Pacific Islander & 2.6 & 1 & 0 & 0 & 1.3 & 1 \\
\hline Other & 2.6 & 1 & 2.7 & 1 & 2.7 & 2 \\
\hline \multicolumn{7}{|l|}{ English as first } \\
\hline \multicolumn{7}{|l|}{ language } \\
\hline Yes & 89.5 & 34 & 94.6 & 35 & 92 & 69 \\
\hline No & 10.5 & 4 & 5.4 & 2 & 8 & 6 \\
\hline \multicolumn{7}{|l|}{ Year in college } \\
\hline Freshman & 18.4 & 7 & 21.6 & 8 & 20 & 15 \\
\hline Sophomore & 39.5 & 15 & 45.9 & 17 & 42.7 & 32 \\
\hline Junior & 28.9 & 11 & 24.3 & 9 & 26.7 & 20 \\
\hline Senior & 13.2 & 5 & 2.7 & 1 & 8 & 6 \\
\hline Graduate student & 0 & 0 & 2.7 & 1 & 1.3 & 1 \\
\hline Did not specify & 0 & 0 & 2.7 & 1 & 1.3 & 1 \\
\hline \multicolumn{7}{|l|}{ Psychological disorder } \\
\hline Yes & 2.6 & 1 & 0 & 0 & 2.7 & 2 \\
\hline No & 97.4 & 37 & 100 & 37 & 97.3 & 73 \\
\hline \multicolumn{7}{|l|}{ Physical abuse* } \\
\hline Yes & 4.2 & 1 & 23.5 & 4 & 12.2 & 5 \\
\hline No & 95.8 & 23 & 76.5 & 13 & 87.8 & 36 \\
\hline \multicolumn{7}{|l|}{ Confederate } \\
\hline 1 & 31.6 & 12 & 35.1 & 13 & 33.3 & 25 \\
\hline 2 & 42.1 & 16 & 27.0 & 10 & 34.7 & 26 \\
\hline 3 & 13.2 & 5 & 27.0 & 10 & 20 & 15 \\
\hline 4 & 13.2 & 5 & 10.8 & 4 & 12 & 9 \\
\hline
\end{tabular}

* $\mathrm{N}=41$ 
Table 2

\begin{tabular}{|c|c|c|c|}
\hline Name of Measures & $\begin{array}{c}\text { Positive } \\
\text { induction } \\
M(S D)\end{array}$ & $\begin{array}{c}\text { Negative } \\
\text { induction } \\
M(S D)\end{array}$ & $\begin{array}{c}\text { Total } \\
M(S D)\end{array}$ \\
\hline \multicolumn{4}{|l|}{ Attachment style } \\
\hline Anxious & $2.95(1.03)$ & $2.99(0.96)$ & $2.97(0.99)$ \\
\hline Avoidant & $3.04(1.28)$ & $2.84(0.96)$ & $2.94(1.13)$ \\
\hline \multicolumn{4}{|l|}{ Baseline accuracy } \\
\hline Overall positive & $84.7(11.8)$ & $90.5(9.50)$ & $90.0(10.7)$ \\
\hline Нарру & $95.4(9.82)$ & $96.6(8.67)$ & $96.0(9.2)$ \\
\hline Surprise & $83.6(19.5)$ & $84.5(19.0)$ & $84.0(19.1)$ \\
\hline Overall negative & $78.1(17.2)$ & $74.8(13.8)$ & $76.5(15.6)$ \\
\hline Anger & $73.7(22.1)$ & $65.8(25.4)$ & $69.8(24.0)$ \\
\hline Sad & $86.0(25.3)$ & $82.0(23.0)$ & $84.0(24.1)$ \\
\hline Fear & $74.6(28.4)$ & $76.6(24.7)$ & $75.6(26.5)$ \\
\hline Neutral & $92.1(14.4)$ & $83.8(23.1)$ & $88.0(19.5)$ \\
\hline \multicolumn{4}{|l|}{ Baseline intensity } \\
\hline Overall positive & $6.98(1.12)$ & $6.86(1.41)$ & $6.92(1.26)$ \\
\hline Нарру & $7.70(1.22)$ & $7.60(1.31)$ & $7.65(1.25)$ \\
\hline Surprise & $6.19(1.46)$ & $6.04(1.83)$ & $6.11(1.64)$ \\
\hline Overall negative & $5.24(1.48)$ & $5.42(1.68)$ & $5.33(1.58)$ \\
\hline Anger & $4.67(1.98)$ & $4.72(2.20)$ & $4.70(2.08)$ \\
\hline Sad & $5.02(1.71)$ & $4.87(1.98)$ & $4.94(1.84)$ \\
\hline Fear & $5.94(1.97)$ & $6.24(2.22)$ & $6.09(2.09)$ \\
\hline Neutral ratings & $0.21(1.39)$ & $0.65(1.44)$ & $0.42(1.42)$ \\
\hline \multicolumn{4}{|l|}{ Task accuracy } \\
\hline Overall positive & $96.7(4.24)$ & $96.8(5.80)$ & $96.7(5.00)$ \\
\hline Happy & $99.2(2.73)$ & $98.9(3.93)$ & $99.1(3.40)$ \\
\hline Surprise & $94.2(8.26)$ & $94.6(9.89)$ & $94.4(9.00)$ \\
\hline Overall negative & $76.7(14.4)$ & $77.0(13.3)$ & $76.8(13.8)$ \\
\hline Anger & $95.5(8.90)$ & $94.2(12.0)$ & $94.9(10.5)$ \\
\hline Sad & $70.3(21.1)$ & $69.5(21.4)$ & $69.9(21.1)$ \\
\hline Fear & $64.3(26.9)$ & $67.4(23.8)$ & $65.9(25.3)$ \\
\hline Neutral & $88.9(12.0)$ & $82.8(17.4)$ & $85.9(15.1)$ \\
\hline \multicolumn{4}{|l|}{ Perceived intensity } \\
\hline Overall positive & $6.40(1.23)$ & $6.54(1.38)$ & $6.47(1.30)$ \\
\hline Happy & $7.05(1.25)$ & $7.19(1.44)$ & $7.12(1.34)$ \\
\hline Surprise & $5.69(1.47)$ & $5.81(1.70)$ & $5.75(1.58)$ \\
\hline Overall negative & $5.36(1.37)$ & $5.57(1.67)$ & $5.46(1.52)$ \\
\hline Anger & $5.69(1.57)$ & $5.87(1.90)$ & $5.78(1.73)$ \\
\hline Sad & $4.37(1.64)$ & $4.48(1.64)$ & $4.42(1.63)$ \\
\hline Fear & $5.94(1.49)$ & $5.87(2.05)$ & $5.91(1.78)$ \\
\hline Neutral ratings & $-0.19(2.02)$ & $-0.58(1.17)$ & $-0.52(1.13)$ \\
\hline
\end{tabular}


Table 3

Mixed-Model ANOVA of Mood-Congruity Effect on Perception Task Accuracy and Perceived Intensity of Emotions Source Perception task accuracy Perceived intensity

\begin{tabular}{lcccccccccc} 
& \multicolumn{1}{c}{$d f$} & $S S$ & $M S$ & $F$ & $p$ & $d f$ & $S S$ & $M S$ & $F$ & $p$ \\
\hline $\begin{array}{l}\text { Between-subjects } \\
\quad \text { Mood conditions }\end{array}$ & 1 & .001 & .001 & .01 & .94 & 1 & 1.04 & 1.04 & \\
$\quad$ Within-subjects & & & & & & & & & & \\
$\quad$ Emotion Valence & 1 & 1.48 & 1.48 & $132.09 *$ & .001 & 1 & 37.86 & 37.86 & $84.51^{*}$ & .001 \\
$\quad$ Emotion Valence & 1 & .001 & .001 & .001 & .96 & 1 & .05 & .05 & .10 & .75 \\
$\quad \quad$ X Conditions & & & & & & & & & & \\
Error & 73 & .77 & .01 & & & 73 & 32.70 & .45 & \\
\hline
\end{tabular}

Note. ${ }^{*}$ Significance level at .05 
Table 4

Mixed-Model ANOVA Analyses on Neutral Accuracy and Perceived Valence on Neutral Stimuli

\begin{tabular}{|c|c|c|c|c|c|c|c|c|c|c|}
\hline \multirow[t]{2}{*}{ Source } & \multicolumn{5}{|c|}{ Neutral accuracy } & \multicolumn{5}{|c|}{ Perceived valence of neutral stimuli } \\
\hline & $d f$ & $S S$ & $M S$ & $F$ & $p$ & $d f$ & $S S$ & $M S$ & $F$ & $p$ \\
\hline \multicolumn{11}{|l|}{ Between subjects } \\
\hline Mood conditions & 1 & .19 & .19 & $5.65^{*}$ & .001 & 1 & .04 & .04 & .01 & .91 \\
\hline \multicolumn{11}{|l|}{ Within subjects } \\
\hline $\begin{array}{l}\text { Pre- and post- } \\
\text { induction }\end{array}$ & 1 & .02 & .02 & .69 & .41 & 1 & 42.75 & 42.75 & $21.52 *$ & .001 \\
\hline $\begin{array}{l}\text { Pre- and post- } \\
\text { induction } \\
\text { X Conditions }\end{array}$ & 1 & .01 & .01 & .20 & .66 & 1 & .82 & .82 & .41 & .52 \\
\hline Error & 73 & 1.80 & .03 & & & 73 & 145.01 & 1.99 & & \\
\hline
\end{tabular}


Table 5

Bivariate correlations of Social Interaction Variables

\begin{tabular}{|c|c|c|c|c|c|c|c|}
\hline \multirow{2}{*}{ 1. Mood condition } & 1 & 2 & 3 & 4 & 5 & 6 & 7 \\
\hline & & & & & & & \\
\hline 2. Response duration & .22 & & & & & & \\
\hline 3. Eye contact count & -.11 & .21 & & & & & \\
\hline 4. Eye contact duration & .13 & $.35^{* *}$ & $.78 * *$ & & & & \\
\hline 5. Comment count & $-.26^{*}$ & -.15 & $.40 * *$ & $.30 * *$ & & & \\
\hline 6. Comment duration & -.02 & $.26 *$ & $.44 * *$ & $.44 * *$ & $.50 * *$ & & \\
\hline 7. Positive affect & $.26 *$ & .19 & $.55^{* *}$ & $.57 * *$ & .18 & $.36 * *$ & \\
\hline 8. Negative affect & .04 & -.16 & $-.23 *$ & -.15 & -.05 & .08 & -.09 \\
\hline
\end{tabular}


Table 6

\begin{tabular}{lccc}
\multicolumn{4}{l}{ Means and Standard Deviations of Social Interaction Variables } \\
\hline Name of Measures & Positive & Negative & Total \\
& induction & induction & $M(S D)$ \\
& $M(S D)$ & $M(S D)$ & \\
\hline Response duration & $22.39(13.97)$ & $16.78(10.95)$ & $19.63(12.80)$ \\
Eye contact count & $6.84(2.75)$ & $7.57(3.73)$ & $7.20(3.27)$ \\
Eye contact & $22.92(11.62)$ & $19.92(12.01)$ & $21.44(11.83)$ \\
duration & & & \\
Comment count & $3.71(1.77)$ & $4.92(2.63)$ & $4.31(2.30)$ \\
Comment duration & $13.21(9.97)$ & $13.57(7.92)$ & $13.39(8.96)$ \\
Positive affect & $1.82(.69)$ & $1.49(.56)$ & $1.65(.65)$ \\
Negative affect & $1.08(.27)$ & $1.05(.33)$ & $1.07(.30)$ \\
\hline
\end{tabular}


Table 7

Hierarchical Multiple Regression Analyses Predicting Social Interaction Variable from Mood Conditions and Perceived Intensity of Positive Emotions.

\begin{tabular}{|c|c|c|c|c|c|c|c|c|c|c|c|c|c|c|}
\hline \multirow[b]{3}{*}{ Predictor } & \multicolumn{14}{|c|}{ Social interaction variables } \\
\hline & \multicolumn{2}{|c|}{$\begin{array}{l}\text { Response } \\
\text { duration }\end{array}$} & \multicolumn{2}{|c|}{$\begin{array}{l}\text { Eye contact } \\
\text { count }\end{array}$} & \multicolumn{2}{|c|}{$\begin{array}{l}\text { Eye contact } \\
\text { duration }\end{array}$} & \multicolumn{2}{|c|}{$\begin{array}{l}\text { Comment } \\
\text { count }\end{array}$} & \multicolumn{2}{|c|}{$\begin{array}{c}\text { Comment } \\
\text { duration }\end{array}$} & \multicolumn{2}{|c|}{ Positive affect } & \multicolumn{2}{|c|}{$\begin{array}{l}\text { Negative } \\
\text { affect }\end{array}$} \\
\hline & $\Delta R^{2}$ & $\beta$ & $\Delta R^{2}$ & $\beta$ & $\Delta R^{2}$ & $\beta$ & $\Delta R^{2}$ & $\beta$ & $\Delta R^{2}$ & $\beta$ & $\Delta R^{2}$ & $\beta$ & $\Delta R^{2}$ & $\beta$ \\
\hline Step 1 & .05 & & .03 & & .07 & & $.08 *$ & & .01 & & .07 & & .001 & \\
\hline Condition & & .22 & & -.07 & & .16 & & $-.26^{*}$ & & -.05 & & $.26^{*}$ & & .04 \\
\hline $\begin{array}{l}\text { Positive } \\
\text { intensity }\end{array}$ & & .07 & & .18 & & .22 & & .11 & & .10 & & .01 & & -.10 \\
\hline Step 2 & .001 & & .003 & & .004 & & .001 & & .01 & & .01 & & .001 & \\
\hline Condition & & .22 & & -.07 & .16 & & & $-.26^{*}$ & & -.05 & & $.26^{*}$ & & .04 \\
\hline $\begin{array}{l}\text { Positive } \\
\text { intensity }\end{array}$ & & .10 & & .21 & .28 & & & .09 & & .01 & & .08 & & -.10 \\
\hline $\begin{array}{l}\text { Condition } x \\
\text { Positive } \\
\text { intensity }\end{array}$ & & -.05 & & -.07 & -.08 & & & .02 & & .14 & & -.10 & & .001 \\
\hline
\end{tabular}

Note. * Significance level at .05 
Table 8

Hierarchical Multiple Regression Analyses Predicting Social Interaction Variable from Mood Conditions and Perceived Intensity of Negative Emotions.

\begin{tabular}{|c|c|c|c|c|c|c|c|c|c|c|c|c|c|c|}
\hline \multirow[b]{3}{*}{ Predictor } & \multicolumn{14}{|c|}{ Social interaction variables } \\
\hline & \multicolumn{2}{|c|}{$\begin{array}{c}\text { Response } \\
\text { duration }\end{array}$} & \multicolumn{2}{|c|}{$\begin{array}{c}\text { Eye contact } \\
\text { count }\end{array}$} & \multicolumn{2}{|c|}{$\begin{array}{c}\text { Eye contact } \\
\text { duration }\end{array}$} & \multicolumn{2}{|c|}{$\begin{array}{l}\text { Comment } \\
\text { count }\end{array}$} & \multicolumn{2}{|c|}{$\begin{array}{c}\text { Comment } \\
\text { duration }\end{array}$} & \multicolumn{2}{|c|}{ Positive affect } & \multicolumn{2}{|c|}{$\begin{array}{c}\text { Negative } \\
\text { affect }\end{array}$} \\
\hline & $\Delta R^{2}$ & $\beta$ & $\Delta R^{2}$ & $\beta$ & $\Delta R^{2}$ & $\beta$ & $\Delta R^{2}$ & $\beta$ & $\Delta R^{2}$ & $\beta$ & $\Delta R^{2}$ & $\beta$ & $\Delta R^{2}$ & $\beta$ \\
\hline Step 1 & .05 & & .06 & & $.12^{*}$ & & $.08 *$ & & .01 & & $.09 *$ & & .004 & \\
\hline Condition & & .22 & & -.07 & & .17 & & $-.26 *$ & & -.05 & & $.27 *$ & & .04 \\
\hline $\begin{array}{l}\text { Negative } \\
\text { intensity }\end{array}$ & & .08 & & $.24 *$ & & $.31 *$ & & .09 & & .08 & & .18 & & -.05 \\
\hline Step 2 & .01 & & .01 & & .001 & & .01 & & .01 & & .01 & & .001 & \\
\hline Condition & & .22 & & -.07 & & .17 & & $-.26 *$ & & -.06 & & $.27 *$ & & .04 \\
\hline $\begin{array}{l}\text { Negative } \\
\text { intensity }\end{array}$ & & .01 & & $.33^{*}$ & & $.32 *$ & & .17 & & .15 & & .21 & & -.02 \\
\hline $\begin{array}{c}\text { Condition } x \\
\text { Negative } \\
\text { intensity }\end{array}$ & & .12 & & -.14 & & -.01 & & -.12 & & -.12 & & -.07 & & -.04 \\
\hline
\end{tabular}

Note. ${ }^{*}$ Significance level at .05 
Figure 1

Mood Ratings for Positive Affect

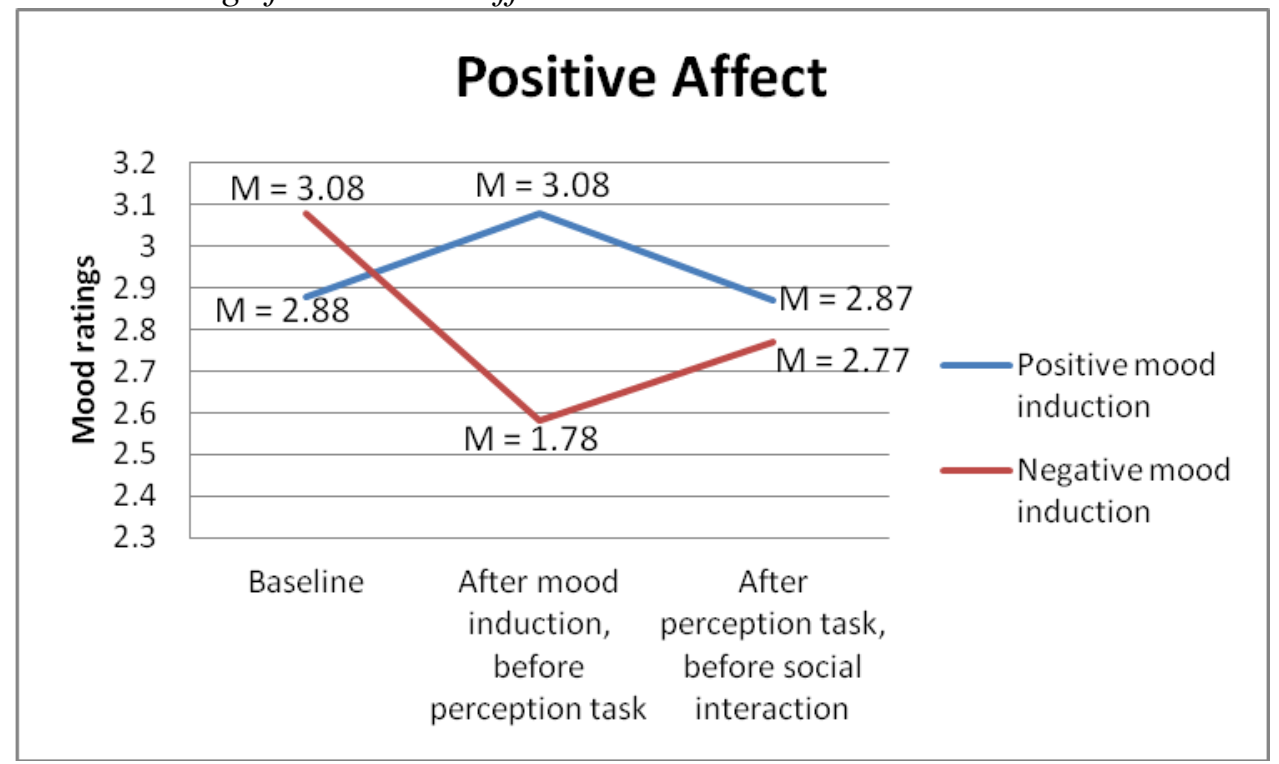

Mood Ratings for Negative Affect

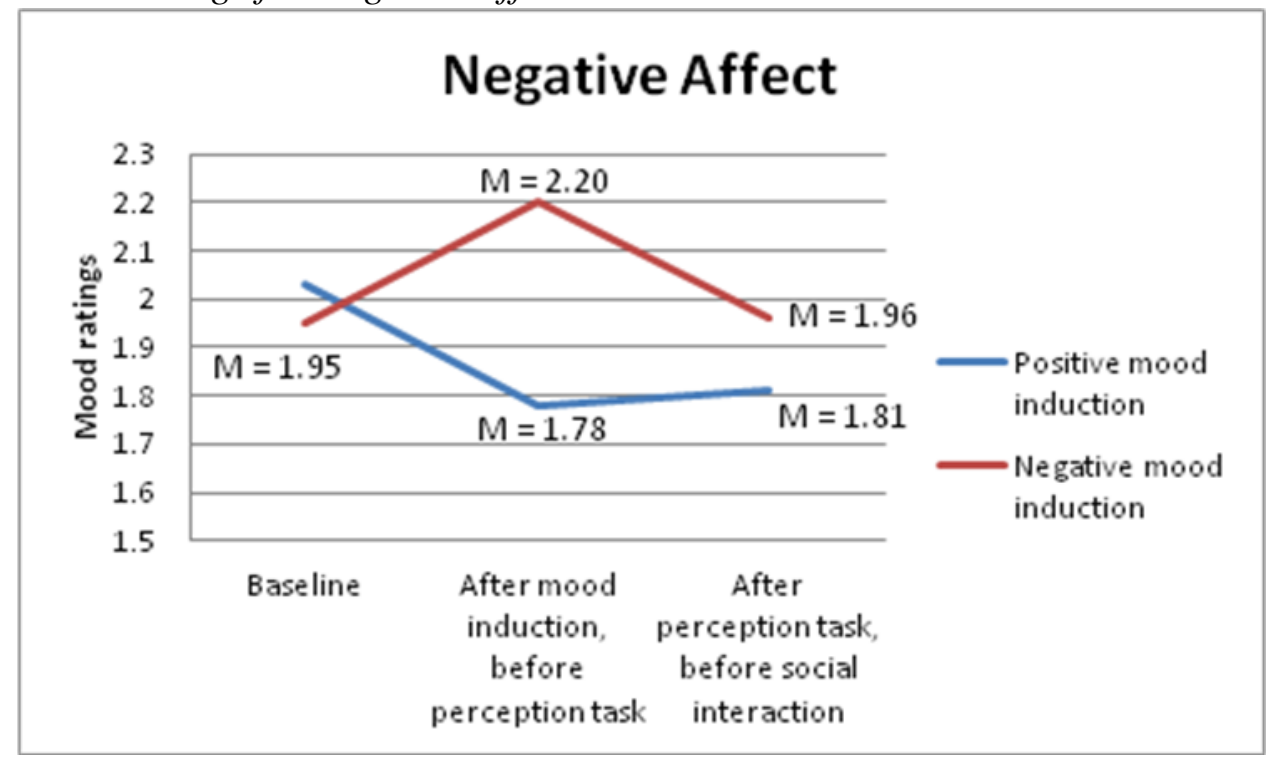


Figure 2

Valence by Race Interaction on Perception Task Accuracy

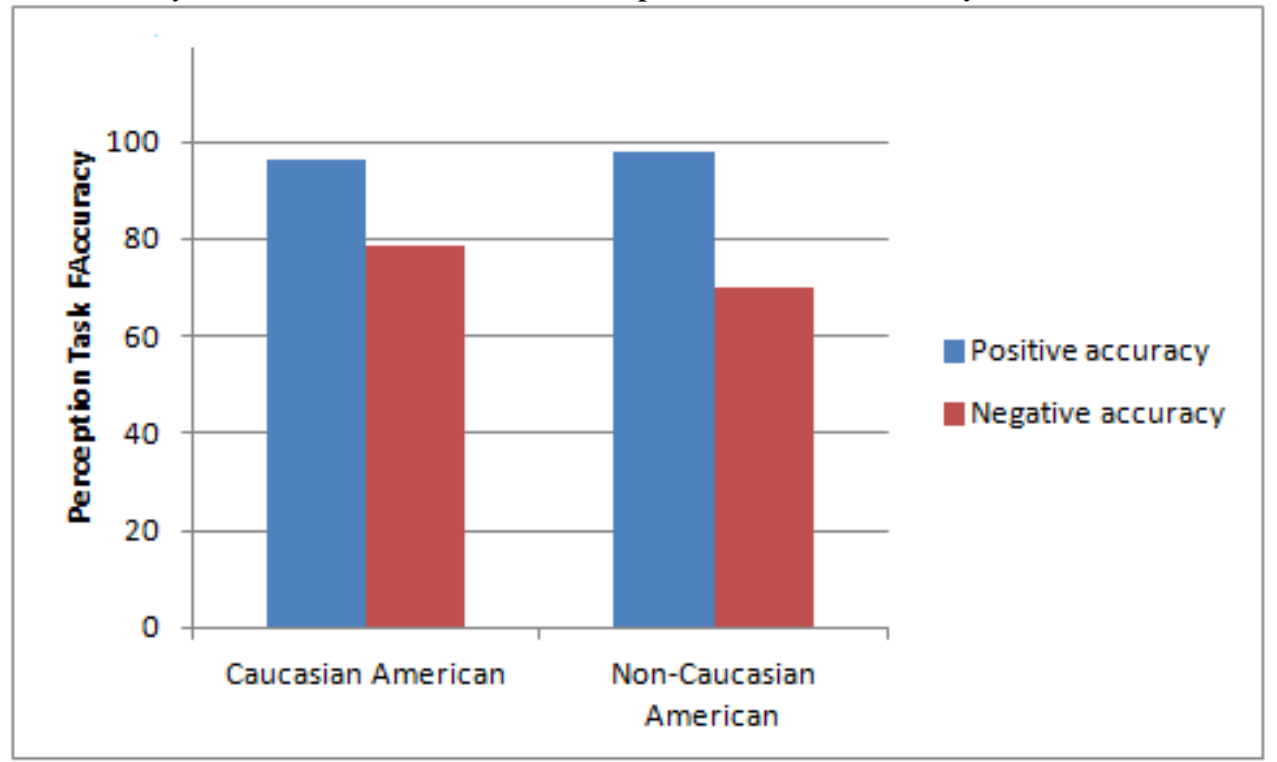


Figure 3

Change in Perceived Valence of Neutral Stimuli across Conditions

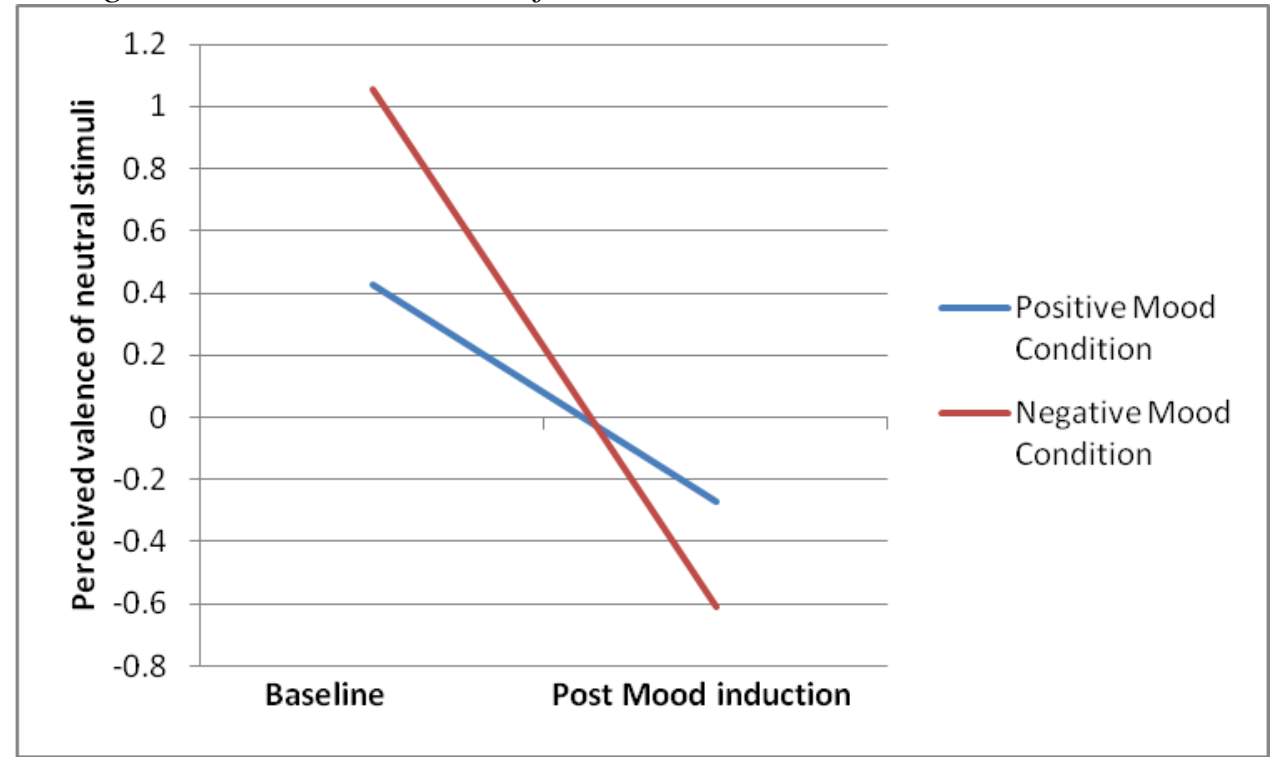




\section{Appendix A: Demographic Questionnaire}

The first part of this survey is background information about you.

1. Age:

2. Gender:
$\square$ Male
$\square$ Female

3. Race/Ethnicity:

$\square$ Caucasian

$\square$ African American

$\square$ Hispanic

$\square$ Asian

$\square$ Pacific Islander

$\square$ Other (Please specify)

4. Country of origin:

5. Is English your first language?

$\begin{array}{ll}\square & \text { Yes } \\ \square & \text { No }\end{array}$

6. Year in college?

7. What is your college major?

$\square$ (Please specify)

$\square$ Undecided

8. Have you been diagnosed or are currently diagnosed with any mood disorder (e.g., depression, bipolar disorder, etc.)?

$\square$ Yes (Please specify)

$\square$ No

9. Have you been physically abused?

$\square$ Yes

$\square$ No 


\section{Appendix B: Brief Mood Introspection Scale (BMIS)}

INSTRUCTIONS: Circle the response on the scale below that indicates how well each adjective describes your present mood.

definitely do not feel do not feel slightly feel definitely feel

\begin{tabular}{|c|c|c|c|c|}
\hline Lively & 1 & 2 & 3 & 4 \\
\hline Drowsy & 1 & 2 & 3 & 4 \\
\hline Happy & 1 & 2 & 3 & 4 \\
\hline Grouchy & 1 & 2 & 3 & 4 \\
\hline Sad & 1 & 2 & 3 & 4 \\
\hline Peppy & 1 & 2 & 3 & 4 \\
\hline Tired & 1 & 2 & 3 & 4 \\
\hline Nervous & 1 & 2 & 3 & 4 \\
\hline Caring & 1 & 2 & 3 & 4 \\
\hline Calm & 1 & 2 & 3 & 4 \\
\hline Content & 1 & 2 & 3 & 4 \\
\hline Loving & 1 & 2 & 3 & 4 \\
\hline Gloomy & 1 & 2 & 3 & 4 \\
\hline Fed up & 1 & 2 & 3 & 4 \\
\hline Jittery & 1 & 2 & 3 & 4 \\
\hline Active & 1 & 2 & 3 & 4 \\
\hline
\end{tabular}


Appendix C: Experiences in Close Relationships-Revised (ECR-R) Questionnaire

In this questionnaire, you'll be asked to answer questions that concern how you generally experience emotionally intimate relationship. Please indicate the extent to which you agree or disagree with each statement by circling a number for each item.

1. I'm afraid that I will lose my partner's love.

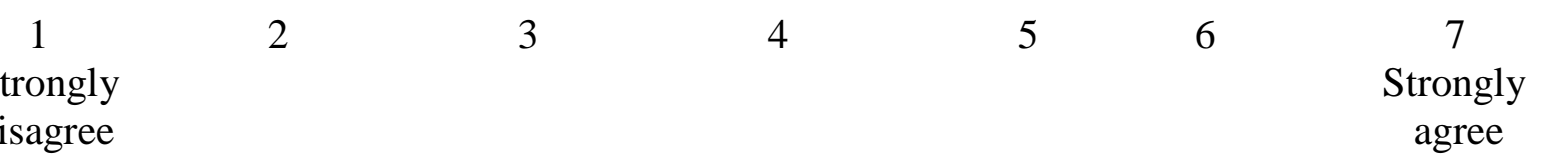

2. I often worry that my partner will not want to stay with me.

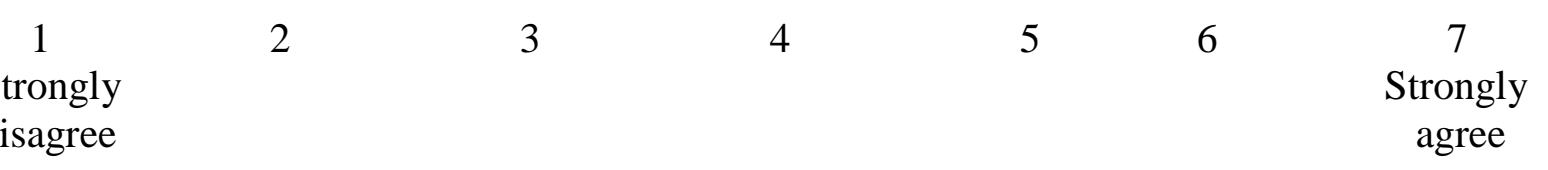

3. I often worry that my partner doesn't really love me.

$\begin{array}{ccccccc}1 & 2 & 3 & 4 & 5 & 6 & 7 \\ \begin{array}{c}\text { Strongly } \\ \text { disagree }\end{array} & & & & & & \begin{array}{c}\text { Strongly } \\ \text { agree }\end{array}\end{array}$

4. I worry that romantic partners won't care about me as much as I care about them.

$\begin{array}{ccccccc}1 & 2 & 3 & 4 & 5 & 6 & 7 \\ \begin{array}{l}\text { Strongly } \\ \text { disagree }\end{array} & & & & & & \begin{array}{c}\text { Strongly } \\ \text { agree }\end{array}\end{array}$

5. I often wish that my partner's feelings for me were as strong as my feelings for him or her.

$\begin{array}{ccccccc}1 & 2 & 3 & 4 & 5 & 6 & 7 \\ \begin{array}{l}\text { Strongly } \\ \text { disagree }\end{array} & & & & & & \begin{array}{c}\text { Strongly } \\ \text { agree }\end{array}\end{array}$

6. I worry a lot about my relationships.

$\begin{array}{lllllll}1 & 2 & 3 & 4 & 5 & 6 & 7\end{array}$

Strongly

agree

disagree 
7. When my partner is out of sight, I worry that he or she might become interested in someone else.
1
2
3
4
5
6
7
Strongly
disagree
Strongly
agree

8. When I show my feelings for romantic partners, I'm afraid they will not feel the same about me.

$\begin{array}{lllllll}1 & 2 & 3 & 4 & 5 & 6 & 7\end{array}$

Strongly

Strongly

disagree agree

9. I rarely worry about my partner leaving me.

$\begin{array}{llllllc}1 & 2 & 3 & 4 & 5 & 6 & 7 \\ \begin{array}{c}\text { Strongly } \\ \text { disagree }\end{array} & & & & & \begin{array}{c}\text { Strongly } \\ \text { agree }\end{array}\end{array}$

10. My romantic partner makes me doubt myself.

$\begin{array}{ccccccc}1 & 2 & 3 & 4 & 5 & 6 & 7 \\ \begin{array}{c}\text { Strongly } \\ \text { isagree }\end{array} & & & & & \begin{array}{c}\text { Strongly } \\ \text { agree }\end{array}\end{array}$

11. I do not often worry about being abandoned.

$\begin{array}{ccccccc}1 & 2 & 3 & 4 & 5 & 6 & 7 \\ \text { Strongly } & & & & & \begin{array}{c}\text { Strongly } \\ \text { agree }\end{array}\end{array}$

12. I find that my partner(s) don't want to get as close as I would like.
1
2
3
4
5
6
7
Strongly
Strongly agree

disagree

13. Sometimes romantic partners change their feelings about me for no apparent reason.

$\begin{array}{ccccccc}1 & 2 & 3 & 4 & 5 & 6 & 7 \\ \begin{array}{l}\text { Strongly } \\ \text { disagree }\end{array} & & & & & \begin{array}{c}\text { Strongly } \\ \text { agree }\end{array}\end{array}$


14. My desire to be very close sometimes scares people away.

$\begin{array}{lllllcc}1 & 2 & 3 & 4 & 5 & 6 & 7 \\ \begin{array}{l}\text { Strongly } \\ \text { disagree }\end{array} & & & & & \begin{array}{c}\text { Strongly } \\ \text { agree }\end{array}\end{array}$

15. I'm afraid that once a romantic partner gets to know me, he or she won't like who I really am.

$\begin{array}{llllllc}1 & 2 & 3 & 4 & 5 & 6 & 7 \\ \begin{array}{c}\text { Strongly } \\ \text { disagree }\end{array} & & & & & \begin{array}{c}\text { Strongly } \\ \text { agree }\end{array}\end{array}$

16. It makes me mad that I don't get the affection and support I need from my partner.

$\begin{array}{ccccccc}1 & 2 & 3 & 4 & 5 & 6 & 7 \\ \text { Strongly } & & & & & \begin{array}{c}\text { Strongly } \\ \text { agree }\end{array}\end{array}$

17. I worry that I won't measure up to other people.

$\begin{array}{llllll}1 & 2 & 3 & 4 & 6 & 7 \\ \begin{array}{c}\text { Strongly } \\ \text { disagree }\end{array} & & & & & \begin{array}{c}\text { Strongly } \\ \text { agree }\end{array}\end{array}$

18. My partner only seems to notice me when I'm angry.

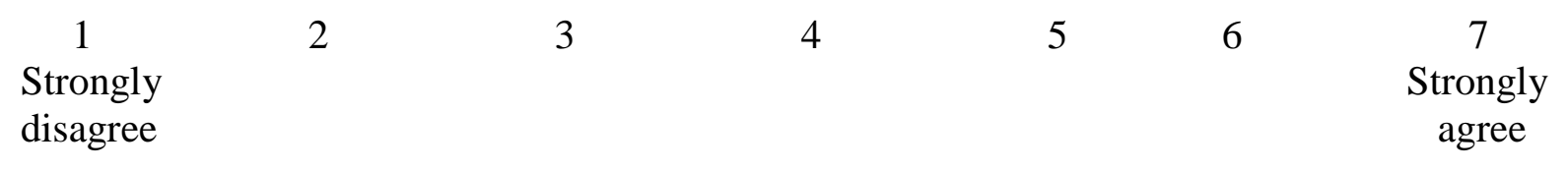

19. I prefer not to show a partner how I feel deep down.

$\begin{array}{llllllc}1 & 2 & 3 & 4 & 5 & 6 & 7 \\ \begin{array}{l}\text { Strongly } \\ \text { disagree }\end{array} & & & & & \begin{array}{c}\text { Strongly } \\ \text { agree }\end{array}\end{array}$

20. I feel comfortable sharing my private thoughts and feelings with my partner.

$\begin{array}{llllllc}1 & 2 & 3 & 4 & 5 & 6 & 7 \\ \begin{array}{l}\text { Strongly } \\ \text { disagree }\end{array} & & & & & \begin{array}{c}\text { Strongly } \\ \text { agree }\end{array}\end{array}$


21. I find it difficult to allow myself to depend on romantic partners.

$\begin{array}{lrrrrrr}1 & 2 & 3 & 4 & 5 & 6 & 7 \\ \begin{array}{l}\text { Strongly } \\ \text { disagree }\end{array} & & & & & \begin{array}{c}\text { Strongly } \\ \text { agree }\end{array}\end{array}$

22. I am very comfortable being close to romantic partners.

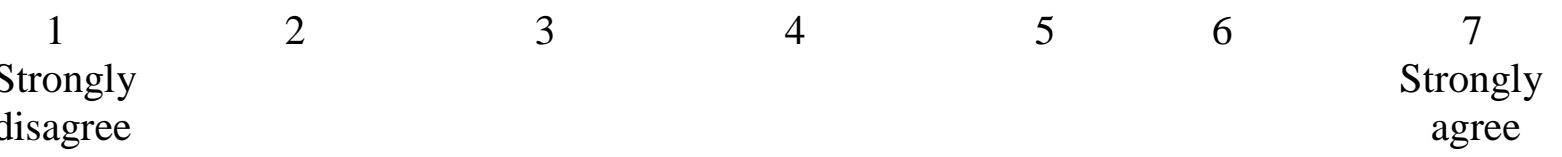

23. I don't feel comfortable opening up to romantic partners.

$\begin{array}{ccccccc}1 & 2 & 3 & 4 & 5 & 6 & 7 \\ \text { Strongly } & & & & & \begin{array}{c}\text { Strongly } \\ \text { agree }\end{array}\end{array}$

24. I prefer not to be too close to romantic partners.

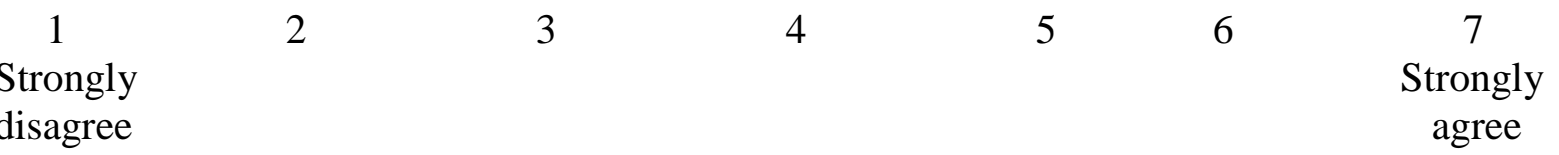

25. I get uncomfortable when a romantic partner wants to be very close.

$\begin{array}{llllllc}1 & 2 & 3 & 4 & 5 & 6 & 7 \\ \begin{array}{l}\text { Strongly } \\ \text { disagree }\end{array} & & & & & \begin{array}{c}\text { Strongly } \\ \text { agree }\end{array}\end{array}$

26. I find it relatively easy to get close to my partner.

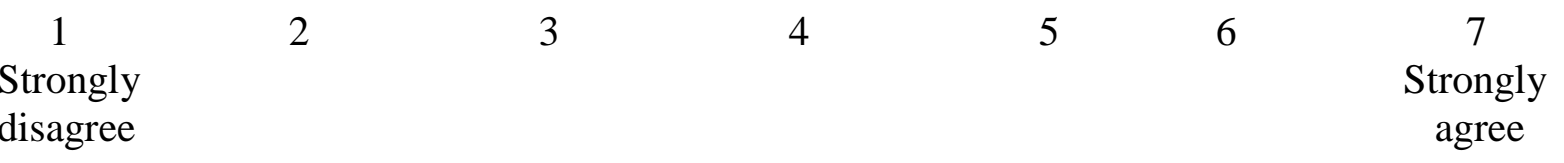

27. It's not difficult for me to get close to my partner.

$\begin{array}{cccccc}1 & 2 & 3 & 5 & 6 & 7 \\ \text { Strongly } & & & & & \begin{array}{c}\text { Strongly } \\ \text { agree }\end{array}\end{array}$


28. I usually discuss my problems and concerns with my partner.

$\begin{array}{lrrrrrr}1 & 2 & 3 & 4 & 5 & 6 & 7 \\ \begin{array}{l}\text { Strongly } \\ \text { disagree }\end{array} & & & & & \begin{array}{c}\text { Strongly } \\ \text { agree }\end{array}\end{array}$

29. It helps to turn to my romantic partner in times of need.

$\begin{array}{ccccccc}1 & 2 & 3 & 4 & 5 & 6 & 7 \\ \text { trongly } & & & & & & \text { Strongly }\end{array}$

disagree agree

30. I tell my partner just about everything.

$\begin{array}{ccccccc}1 & 2 & 3 & 5 & 6 & 7 \\ \text { trongly } & & & & & \begin{array}{c}\text { Strongly } \\ \text { agree }\end{array}\end{array}$

31. I talk things over with my partner.

$\begin{array}{lllllll}1 & 2 & 3 & 4 & 5 & 6 & 7\end{array}$

Strongly

disagree

Strongly agree

32. I am nervous when partners get too close to me.

$\begin{array}{llllllc}1 & 2 & 3 & 4 & 5 & 6 & 7 \\ \begin{array}{l}\text { Strongly } \\ \text { disagree }\end{array} & & & & & \begin{array}{c}\text { Strongly } \\ \text { agree }\end{array}\end{array}$

33. I feel comfortable depending on romantic partners.

$\begin{array}{lllllcc}1 & 2 & 3 & 4 & 5 & 6 & 7 \\ \begin{array}{c}\text { Strongly } \\ \text { disagree }\end{array} & & & & & \begin{array}{c}\text { Strongly } \\ \text { agree }\end{array}\end{array}$

34. I find it easy to depend on romantic partners.

$\begin{array}{ccccccc}1 & 2 & 3 & 4 & 5 & 6 & 7 \\ \begin{array}{c}\text { Strongly } \\ \text { isagree }\end{array} & & & & & \begin{array}{c}\text { Strongly } \\ \text { agree }\end{array}\end{array}$


35. It's easy for me to be affectionate with my partner.

$\begin{array}{ccccccc}1 & 2 & 3 & 4 & 5 & 6 & 7 \\ \begin{array}{l}\text { Strongly } \\ \text { disagree }\end{array} & & & & & \begin{array}{c}\text { Strongly } \\ \text { agree }\end{array}\end{array}$

36. My partner really understands me and my needs.

$\begin{array}{ccccccc}1 & 2 & 3 & 4 & 5 & 6 & 7 \\ \text { Strongly } & & & & & \begin{array}{c}\text { Strongly } \\ \text { agree }\end{array}\end{array}$


Appendix D: Scripts for Positive and Negative Event Recalling

\section{Positive event recalling}

"Now, I'm going to ask you to think of a very positive experience that you could describe to me. So during the next two minutes, please think of a personal experience that has happened to you that made you very happy, and that still really makes you feel really good when you think about. Once you think of something that you'd be willing to describe briefly to me, let me know. Again, it can be something that happened very recently or something that happened in your more distant past, but it should be something that still makes you happy. I'll give you two minutes, then start recording your response."

After two minutes, the experimenter will ask:

“ 1. Would you please describe your experience in detail? For example, you can describe what happened, people involved, and how it made you feel.

2. Is there anything else about the experience that made you feel good?"

\section{Negative event recalling}

"Now, I am going to ask you to recall a personal experience that happened to you. I want you to take the next two minutes and think about an upsetting event that still really bothers you and that you'd be willing to describe briefly to me. It can be something that happened very recently or something that happened in your past, but it should be something that is still upsetting. I'll give you two minutes to think of something and I'll start recording after the 2 minutes is up."

After two minutes, the experimenter will ask:

“ 1. Would you please describe your experience in detail? For example, you can describe what happened, people involved, and how it made you feel.

2. Is there anything else about the experience that was upsetting?" 
Appendix E: Ekman Photos and Questions in the Emotion Perception Task
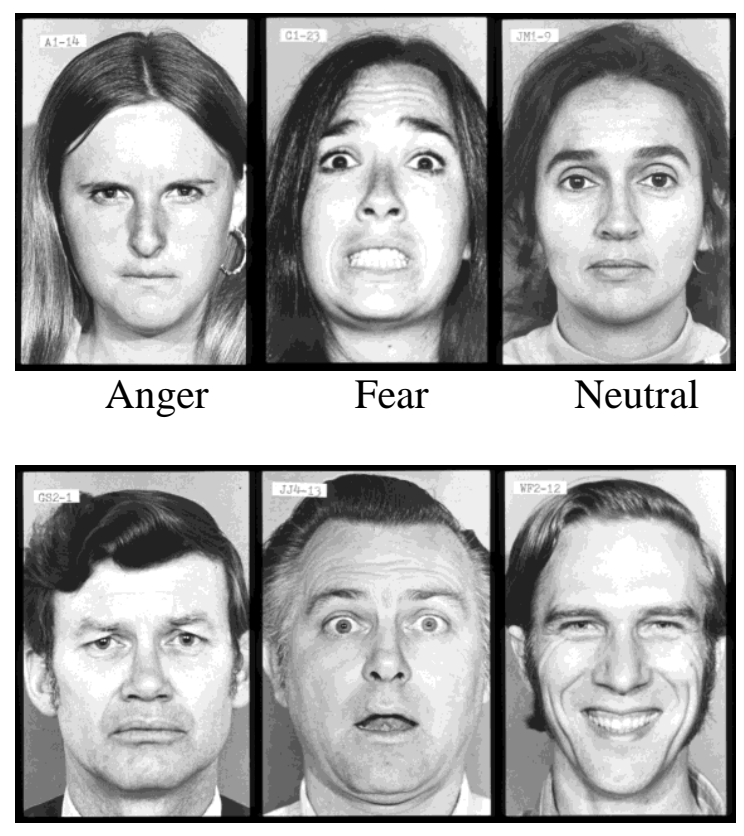

Sad

Surprise

Happy

Questions followed each face stimulus:

i. Which emotion is the face expressing?
A. Happy
B. Sad
C. Neutral
D. Anger
E. Surprise
F. Fear

iia. How intense is the emotion?

Not at all intense

iib. If you chose "neutral", what is the valence of the emotion?

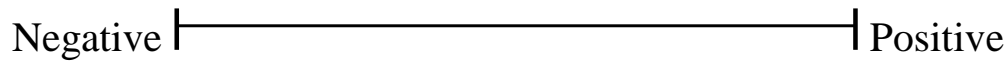




\section{Appendix F: Coding sheet for social interaction}

\section{Background on the social interaction task:}

The confederate will enter the room and introduce him/herself as another researcher in the lab. Then, the confederate will launch a series of scripted icebreaker comments in an attempt to initiate a social conversation with the participants. Also, the confederate will ask participants for a favor. For observation purpose, the confederate's act will be broken down into a series of standard units, demarcated by a standard comment. In sequence, the confederate will deliver the following scripts:

1. Confederate enters the room and says ' $O$ h, I am sorry. I didn't realize that someone is in this room. Are you here for the psychology study?"

2. As the participant replies, the confederate asks "Is it over?"

i. If yes/I think so/probably, etc., then say "OK, good, I just need a table to sort this stack of articles. Would you mind if I sit here?"

ii. If no/I don't think so, etc., then say, "Let me check with someone. (then ask Frankie, who says "yeah, that's fine, we're done."). After Frankie responds, turn to the participant and say "I need a table to sort this stack of articles, would you mind if I sit here?"

3. The confederate will sit down and say "By the way, I am one of the undergraduate researchers in this lab. So, how was the study?"

i. If the participant gives a positive comment, say "that's cool/good..."

ii. If the participant gives a negative comment, say "Well, at least you are done with it."

4. The confederate says "I need to alphabetize this stack of articles by the authors' last name. Can you help me out? You don't have to. . No pressure"

5. If the participant agrees to help, the confederate will give the participant the stack of exactly 10 articles to sort. If the participant refuses to help, the confederate will sort the articles by him/herself. In either case, the confederate then asks the participant "Are you a psychology major?"

6. As the participant answers, the confederate says "What classes are you taking now?"

7. As the participant responds, the confederate says "How are they going?"

General instruction:

Please watch the video for multiple times as you do your coding. When you watch the video for the first time, you can focus on the global codes (underlined) and try to get a feel of the general social interaction style of the participant. Once you get the global codes, you can repeat the video to capture the participant's comments and eye contacts (bolded) and record the duration accordingly. You may repeat the video for as many times as you need to get these codes. You can also use the "rewind" or "fast forward" functions to help you precisely get the codes and record the duration. After that, please rate the positive and negative affect of the participant based on his/her tone of voice, facial expression and body movement. Finally, note any unusual/strange circumstance that is worth concerning. 
SOCIAL INTERACTION CODING SYSTEM

Subject \#

Coder:

You will code the social interaction style of the participant on three domains: 1) agreeableness;

2) engagement; and 3) affect. Here are the instructions:

\section{Agreeableness}

a. Did the participant let the confederate into the room?

- $0=$ no

- $1=$ yes

b. Did the participant help the confederate to sort articles?

- $0=$ reject the initial request

- $\quad 1=$ help upon initial request, but no further volunteering

- $2=$ agree to the initial request and offers additional help to the confederate after he/she complete the original request

c. Did the participant respond to standard question $5,6,7$ ? $(0=$ no; $1=$ yes $)$

- $\quad$ Question 5 (Psy Major?)

- Length of the response seconds

- $\quad$ Question 6 (What Classes?)

- Length of the response seconds

- $\quad$ Question 7 (How are they?)

- Length of the response seconds 


\section{Engagement}

a. Please record all the eye contact that the participant made and note the duration of each eye contact in second:

i . when confederate asked he/she the standard questions (count the total \#)

- duration of the eye contact(s)

i i . when he/she responded to the standard questions (count the total \#)

- duration of the eye contact(s)

i i i . when he/she initiated an unrelated comment (count the total \#)

- duration of the eye contact(s)

b. Please record all incidents for which the participant initiates new comments that are irrelevant to the standard questions (i.e., anything unrelated to their major, the classes they are taking and how they feel about the classes) and note the duration of each comment.

- Number of new comment(s)

- Duration of the comment(s)

c. Please note the approach behavior(s) of the participant.

i . Did the participant move the chair close to the confederate?

- $0=$ no

- $1=$ yes

i i . Did the participant clear the table for the confederate?

- $0=n o$

- $1=$ yes 


\section{Affect}

a. Please rate the participant's POSITIVE affect based on his/her tone of voice, facial expression and body movement (Circle your rating).

\begin{tabular}{|l|l|l|l|l|}
\hline & \multicolumn{1}{|c|}{$\mathbf{1}$} & \multicolumn{1}{|c|}{$\mathbf{3}$} & \multicolumn{1}{|c|}{$\mathbf{4}$} \\
\hline Tone of voice & $\begin{array}{l}\text { monotonous or flat } \\
\text { tone of voice (i.e. no } \\
\text { fluctuations in tone) }\end{array}$ & $\begin{array}{l}\text { slightly lilting tone of } \\
\text { voice }\end{array}$ & $\begin{array}{l}\text { higher pitch } \\
\text { talking faster or louder than } \\
\text { usual }\end{array}$ & $\begin{array}{l}\text { laughing, giggling } \\
\text { singsong quality } \\
\text { enthusiastic or excited tone }\end{array}$ \\
\hline $\begin{array}{l}\text { Facial } \\
\text { expressions }\end{array}$ & $\begin{array}{l}\text { neutral expression } \\
\text { with no visible } \\
\text { positive affect }\end{array}$ & $\begin{array}{l}\text { forced smile (angled } \\
\text { upward movement of lip } \\
\text { corners, but not } \\
\text { movement around the } \\
\text { eyebrows) }\end{array}$ & $\begin{array}{l}\text { Some weak polite/social } \\
\text { smiles (brief, usually in } \\
\text { response to other's } \\
\text { comments) }\end{array}$ & $\begin{array}{l}\text { genuine smile (angled upward } \\
\text { movement of lip corners, raised check, } \\
\text { contraction of muscles around the eyes) }\end{array}$ \\
\hline Body movements \\
$\begin{array}{l}\text { minimum body } \\
\text { than those needed } \\
\text { for completely the } \\
\text { task }\end{array}$ & $\begin{array}{l}\text { body movements to } \\
\text { make self more } \\
\text { comfortable (e.g. leaning } \\
\text { forward, adjusting sitting } \\
\text { posture) }\end{array}$ & $\begin{array}{l}\text { moderate amount of body } \\
\text { movements (e.g. gesturing } \\
\text { while talking) }\end{array}$ & $\begin{array}{l}\text { body movements or gestures that } \\
\text { indicate happiness (e.g. cover the mouth } \\
\text { when laughing, tapping on the table } \\
\text { rhythmically while whistling) }\end{array}$ \\
\hline
\end{tabular}


b. Please rate the participant's NEGATIVE affect based on his/her tone of voice, facial expression and body movement (Circle your rating).

\begin{tabular}{|c|c|c|c|c|}
\hline & 1 & 2 & 3 & 4 \\
\hline Tone of voice & $\begin{array}{l}\text { generally neutral tone } \\
\text { of voice }\end{array}$ & $\begin{array}{l}\text { tired voice } \\
\text { slow pace of speech } \\
\text { decreasing volume }\end{array}$ & $\begin{array}{l}\text { Sadness: } \\
\text { Low and soft voice, } \\
\text { dropping off at the end } \\
\text { Sighs } \\
\text { Anger/contempt/disgust: } \\
\text { Insistent, defiant tone of } \\
\text { voice } \\
\text { Pitch and volume } \\
\text { increase }\end{array}$ & $\begin{array}{l}\text { Sadness: } \\
\text { heavy sighing } \\
\text { crying and whining } \\
\text { Anger/contempt/disgust: } \\
\text { harsh, sarcastic or hostile tone of voice } \\
\text { raises voice } \\
\text { swears }\end{array}$ \\
\hline
\end{tabular}




\begin{tabular}{|c|c|c|c|c|}
\hline Facial expressions & $\begin{array}{l}\text { no negative affect } \\
\text { expression at all }\end{array}$ & $\begin{array}{l}\text { look bored } \\
\text { eyes gaze randomly } \\
\text { moving around the } \\
\text { surroundings of the } \\
\text { room aimlessly } \\
\text { eyes partially closed } \\
\text { and blinking a lot } \\
\text { yawning }\end{array}$ & $\begin{array}{l}\text { Sadness: } \\
\text { Slight frowning (lip } \\
\text { corners pulled down, } \\
\text { lower lip depressed) } \\
\text { inner corners of } \\
\text { eyebrows may be raised } \\
\text { and come together } \\
\text { bottom lip may protrude } \\
\text { out as if pouting or } \\
\text { frowning } \\
\text { Anger/contempt/disgust: } \\
\text { eyelids tighten or } \\
\text { narrow } \\
\text { mouth or jaw set; lips } \\
\text { pressed, tightened, or } \\
\text { protruding; } \\
\text { eyebrows may be } \\
\text { slanted down slightly or } \\
\text { drawn together }\end{array}$ & $\begin{array}{l}\text { Sadness: } \\
\text { frequent frowning (lip corners pulled } \\
\text { down, lower lip depressed) } \\
\text { tears in the eyes } \\
\text { eyes may crinkle and lower eyelids may } \\
\text { be raised } \\
\text { eyes may be downcast or droopy } \\
\text { Anger/contempt/disgust: } \\
\text { clenched jaw or teeth } \\
\text { narrowed eyes and pursed lips } \\
\text { eye-rolling or scoff }\end{array}$ \\
\hline Body movements & $\begin{array}{l}\text { no body movement } \\
\text { or gestures indicative } \\
\text { of negative } \\
\text { emotionality }\end{array}$ & $\begin{array}{l}\text { body movements } \\
\text { indicative of boredom } \\
\text { or fatigue (e.g., hands } \\
\text { support head, } \\
\text { scratching face, } \\
\text { decreasing stature with } \\
\text { slumped shoulder, } \\
\text { back and head) }\end{array}$ & $\begin{array}{l}\text { body movements } \\
\text { indicative of } \\
\text { uneasiness/frustration } \\
\text { (e.g. physical passivity } \\
\text { and withdrawal, } \\
\text { randomly flip through } \\
\text { the articles) }\end{array}$ & $\begin{array}{l}\text { body movements or gesture indicative of } \\
\text { negative emotionality (e.g. collapsed } \\
\text { torso, nervous fidgeting, throws up hands) }\end{array}$ \\
\hline
\end{tabular}

Was there anything unusual/strange/noteworthy about the recording? 